OPEN ACCESS

Edited by:

Maroun Khoury,

University of the Andes, Chile

Reviewed by:

Maikel Peppelenbosch,

Erasmus Medical Center, Netherlands

Kenneth Beaman,

Rosalind Franklin University of

Medicine and Science, United States

*Correspondence:

Valerie Planat-Benard

valerie.planat@inserm.fr

Specialty section:

This article was submitted to Immunological Tolerance and Regulation,

a section of the journal

Frontiers in Immunology

Received: 06 November 2020 Accepted: 12 April 2021

Published: 30 April 2021

Citation:

Planat-Benard V, Varin A and Casteilla L (2021) MSCs and Inflammatory Cells Crosstalk in

Regenerative Medicine: Concerted Actions for Optimized Resolution

Driven by Energy Metabolism.

Front. Immunol. 12:626755. doi: $10.3389 /$ fimmu.2021.626755

\section{MSCs and Inflammatory Cells Crosstalk in Regenerative Medicine: Concerted Actions for Optimized Resolution Driven by Energy Metabolism}

\author{
Valerie Planat-Benard*, Audrey Varin and Louis Casteilla
}

RESTORE, University of Toulouse, UMR 1031-INSERM, 5070-CNRS, Etablissement Français du Sang-Occitanie (EFS), Université Paul Sabatier, Toulouse, France

Mesenchymal stromal cells (MSCs) are currently widely used in cell based therapy regarding to their remarkable efficacy in controlling the inflammatory status in patients. Despite recent progress and encouraging results, inconstant therapeutic benefits are reported suggesting that significant breakthroughs in the understanding of MSCs immunomodulatory mechanisms of action remains to be investigated and certainly apprehended from original point of view. This review will focus on the recent findings regarding MSCs close relationship with the innate immune compartment, i.e. granulocytes and myeloid cells. The review will also consider the intercellular mechanism of communication involved, such as factor secretion, cell-cell contact, extracellular vesicles, mitochondria transfer and efferocytosis. Immune-like-properties of MSCs supporting part of their therapeutic effect in the clinical setting will be discussed, as well as their potentials (immunomodulatory, anti-bacterial, anti-inflammatory, anti-oxidant defenses and metabolic adaptation...) and effects mediated, such as cell polarization, differentiation, death and survival on various immune and tissue cell targets determinant in triggering tissue regeneration. Their metabolic properties in term of sensing, reacting and producing metabolites influencing tissue inflammation will be highlighted. The review will finally open to discussion how ongoing scientific advances on MSCs could be efficiently translated to clinic in chronic and age-related inflammatory diseases and the current limits and gaps that remain to be overcome to achieving tissue regeneration and rejuvenation.

Keywords: mesenchymal stromal cells (MSCs), inflammation, macrophage, immunomodulation, metabolic reprogramming, cell therapy, regenerative medicine

\section{INTRODUCTION}

Mesenchymal stromal cells (MSCs) are present in all tissues as a major structural and connective component sensing microenvironment signals and acting to maintain tissue homeostasis. They represent a heterogeneous cell population among which the presence of a canonic mesenchymal stem cell subpopulation is largely questioned. The role of such a multipotent progenitor 
subpopulation is out of the scope of the present review that will be focused on the stromal and supportive functions of MSCs. Cell-based therapy harnesses these activities to orchestrate tissue reconstruction and rescue functional and structural integrity upon injury and disease. Recent findings outline that metabolism is driving MSCs mobilization and responses and that immune cells, also present in all tissues, remain one of the privileged targets, acting together for driving the therapeutic outcome. Based on clinical results using MSCs as advanced medicinal products (ATMP) a focus will be made on the immunomodulatory effect observed in various regenerative medicine applications. The object of the present review is thus to provide an overview of the recent progress in deciphering cellular, molecular and metabolic communication between MSCs and innate immunity cells. The positioning of MSCs as a component of the immune system will be questioned. We will discuss how MSCs and macrophages organize into a highly interconnected network where cell metabolism and energy management reflect and modulate both mesenchymal and immune functions. Finally, the discussion will open to novel consideration of such metabolic immune-mesenchymal axis to maintain or restore tissue homeostasis.

\section{CLINICAL OUTCOMES FROM THE USE OF MSCs IN INFLAMMATORY/ IMMUNE DISEASES}

MSCs are good candidates for cell therapy to treat inflammatory diseases such as graft versus host disease (GVHD) (1), sepsis (2) and inflammatory bowel diseases (IBD) $(3,4)$ based on their capability to resolve inflammation and promote tissue repair by modulating endogenous tissue and immune cells such as macrophages, neutrophils, and natural killer (NK) cells.

The first therapeutic use of MSCs was to treat severe GVHD. Severe GVHD is a life-threatening complication after allogeneic transplantation with hematopoietic stem cells (HSCs) that is characterized by the activation of the immune system with systemic inflammation and tissue injury. Steroids are the firstline treatment for established GVHD however, 50\% of patients are non-responders and have a poor outcome (5). MSCs support proliferation and differentiation of HSCs in the bone marrow, promote HSCs engraftment in animal model and can decrease inflammation (6). Therefore, MSCs were seen as good candidates to treat steroid-resistant acute GVHD (SRaGVHD). In a phase II multicenter European study, 55 patients with steroid-resistant acute severe GVHD were treated with bone marrow-derived MSCs (BM-MSCs). 39 out of the 55 patients responded to the treatment and the survival of patients with complete response were significantly higher and transplantation-related mortality after injection was significantly lower than in non- or partial responder patients (7). Moreover, in a phase III, prospective, single-arm, multicenter study, pediatric patients with primary SRaGVHD where treated with allogenic BM-MSCs. This study demonstrated that MSCs infusions significantly improve overall response in pediatric patients with SR-aGVHD compared with derived historical rates and are well tolerated with no safety issues. In addition, the observed improved response at day 28 was strongly associated with significantly improved survival through day 180 (8). This report supports previous studies that demonstrated the beneficial effect of BMMSCs on SR-GVHD $(9,10)$. However, a recent meta-analysis questioned the positive effect of MSCs on GVHD. Indeed, injection of MSCs can decrease chronic GVHD but not protect from acute GVHD. Similarly, another meta-analysis demonstrated that the studies analyzing the effect of MSCs on GVHD are low-quality evidence and the results of the current published random clinical trials do not support the conclusion that MSCs are effective therapy for GVHD (11). Such divergences may come from the time of transplantation. Indeed, umbilical-derived MSCs (UC-MSCs) and MSCs infused after HSCs can reduce chronic GVHD, favor HSCs engraftment and decrease incidence rate of relapse and death whereas treatment with BM-MSCs and MSCs before HSCs transplantation have a negative effect on patient survival (12). Taken together, the absence of robust effect of MSCs, due to the small number of studies and the limited number of enrolled patients indicate that high-quality controlled clinical trial as well as a more refined understanding of MSCs action are required to prove the beneficial effect of MSCs on GVHD treatment.

More robust results were obtained in inflammatory bowel diseases (IBD), Crohn's disease and ulcerative colitis where MSCs demonstrate a great efficacy. IBD is characterized by a chronic and destructive inflammation of the gastrointestinal tract. Indeed, IBD pathogenesis is associated with IL-23 and IL-12 pro-inflammatory cytokines that promote in the intestine the switch of $\mathrm{T}$ lymphocytes toward a Th1 pro-inflammatory profile and the formation of Th17 lymphocytes playing an important role in inflammation and tissue damage in autoimmune diseases such as Crohn diseases (13). The Th17 T cells produce IL-17 that locally stimulates chemokine production attracting macrophages, neutrophils and increasing local inflammation (14). In a different experimental model, administration of MSCs protects against colitis by regulating the Th1/Th17 response, increasing the number of FoxP3 positive regulatory $\mathrm{T}$ cells in the colon and in the mesenteric lymph node. MSCs also modulate inflammation by decreasing proinflammatory cytokines such as TNF- $\alpha$, IL-12 and IFN- $\gamma$ and increasing IL-10 in the colon $(15,16)$. MSCs seem to target directly the Th-17 $\mathrm{T}$ cells increasing their expression of FoxP3 mRNA, switching them in regulatory $T$ cells, inhibiting their production of inflammatory cytokines. In 2018, the European Commission approved the first MSCs pharmaceutical product to treat Crohn's-related enterocutaneous fistular diseases, following several clinical trials demonstrating that local injection of BMMSCs $(17)$ or ASCs $(18,19)$ can induce remission in patients that previously failed with classical therapies. More than $50 \%$ of the MSCs-treated patients present a complete closure of all fistula tracts that was sustained at 52 weeks post-treatment. In addition, 
beneficial effects of MSCs were demonstrated in ulcerative colitis (20).

Despite the absence of phase 3 clinical trial, in vivo preclinical and phase 1 clinical studies seem to demonstrate that MSCs could also be a new treatment for acute inflammatory diseases such as sepsis (21). Sepsis is a life-threatening syndrome resulting in shock and multiple organ dysfunction due to microbial infection. The loss of immune homeostasis induced by the presence of the pathogens drive a hyperproduction of proinflammatory cytokines as well as anti-inflammatory molecules by the innate immune cells that induce the "cytokine storm" that is associated with the multi-organ failure and death. A metaanalysis demonstrated that in preclinical sepsis models, treatment with MSCs decreases drastically the mortality and the general inflammation of septic animals (22). In human, several phase I clinical trials concluded that intravenous injection of umbilical, bone marrow- or adipose tissue-derived MSCs is safe and does not induce harmful side effect on patients (23-25). In a single-center and randomized study, one intravenous injection of MSCs in severe neutropenic patients with septic shock reduced the Sequential Organ Failure Assessment score and significantly increased survival rates compared to the conventional treatment group. However, MSCs treatment did not prevent long-term death from sepsisrelated organ failures (26). Moreover, several studies demonstrated that intravenous injection of MSCs can modify the immune response during sepsis. Indeed, intravenous injection of allogenic BM-MSCs or adipose-derived mesenchymal stromal cells (ASCs) on septic shock patients had none or mild effect on increased pro-inflammatory cytokines and biomarkers but MSCs injection induced a timedepend decreased of pro-inflammatory cytokines as well as procoagulant factors in patients on septic shock $(24,27)$.

Similarly, multiple human clinical studies reported that MSCs administration is safe for patients with severe pulmonary diseases such as acute respiratory distress syndrome (ARSD), acute lung injury (ALI) $(25,28)$ or chronic obstructive pulmonary disease (COPD). However, due to the relatively small number of patients enrolled in clinical trial, efficacy of MSCs treatment for severe pulmonary diseases has not been demonstrated yet (29). Interestingly, a recent study demonstrated safety and efficacy of MSCs as treatment of Influenza A (H7N9)-induced ARDS (30). Indeed, the MSCstreated group have a significantly higher survival rate compared to the control group. At the 1 year follow-up, MSCs-treated patients have an improvement of chest CT scans and they presented no decline in pulmonary functions nor deleterious effects link to the treatment. Therefore, MSCs have been rationally considered and already tested as a possible treatment for Covid-19 (31). Despite great progress in the knowledge of MSCs biology, conclusions from clinical trials using MSCs in inflammatory diseases reveal that no adverse events are reported and beneficial effect can be expected even though consistent and robust clinical improvement is not yet reached. Not all patients respond to treatment suggesting that there is more to understand about their mechanisms of action. To that end their broad reactivity with the immune system remain to be explored to provide substantial advance in MSCs therapy.

\section{MSCs AND INFLAMMATORY RESPONSE: A QUESTION OF CELL DIALOGUE}

The immunomodulatory potential of MSCs is thus supported by experimental and clinical data and rely on an organized and complex network interfacing immune cells with MSCs. While immunosuppressive activity of MSCs on adaptive immune cells is already largely documented (32), and in line with conclusions from clinical trial findings, we will focus here on innate immune system cells.

MSCs play a critical role in the two phases of inflammation essential for an effective healing process: the early acute phase that initiate inflammation and its subsequent resolution necessary to achieve the repair process (Figure 1). Neutrophils are the first line of defense against pathogens and tissue injury that are massively recruited to the site of infection or damaged tissue. Several papers functional interaction between MSCs and neutrophils allows an efficient mobilization of immune cells. LPS (lipopolysaccharide)-stimulated glandular MSCs increased the recruitment of polymorphonuclear leucocytes through the secretion of the IL- 8 chemokine and macrophage migration inhibitory factors (MIF) but increased also the life span and the anti-bacterial activity of neutrophils (33). Similar results were obtained with human BM-MSCs and ASCs. Indeed, MSCs increase recruitment and direct migration, increase life span and enhanced phagocytosis and respiratory burst activity of neutrophils. Effects of MSCs are dependent on soluble factors such as GM-CSF or INF- $\gamma$ (34), IL-8 and MIF (33) as well as exosomes secretion $(35,36)$. MSCs can also display an indirect effect on neutrophil by modulating other immune cells as demonstrated by $\mathrm{Hu}$ et al. showing that MSCs induced IL-17 production by activated $\mathrm{T}$ cells stimulate neutrophil phagocytic activity (37).

Other innate immune partners that strongly interact with MSCs are monocyte and macrophage cells. Via direct and indirect effects, MSCs thus promote a pro-resolutive environment. In vitro studies demonstrated that MSCs trigger the polarization of macrophages from a pro-inflammatory M1 phenotype to an anti-inflammatory-like M2 phenotype (38) through the production of immunosuppressive molecules and metabolites, such as prostaglandin E2 (PGE2) (39-42) and tumor necrosis factor-stimulated gene 6 protein (TSG6) (43, 44). They also attract monocytes and macrophages through the release of chemokines such as CCL2, CCL3 and CCL12 into inflamed tissue and support wound repair (45).

This is consistent with in vitro data where MSCs support monocyte survival through direct interaction while increasing expression of M2 markers, phagocytic capacity and antiinflammatory cytokines secretion via the production of PGE2 (46). MSCs also inhibit monocyte differentiation into dendritic cells (DC) and macrophages, decrease their phagocytosis functions and block their capacity to stimulate $\mathrm{T}$ cell 


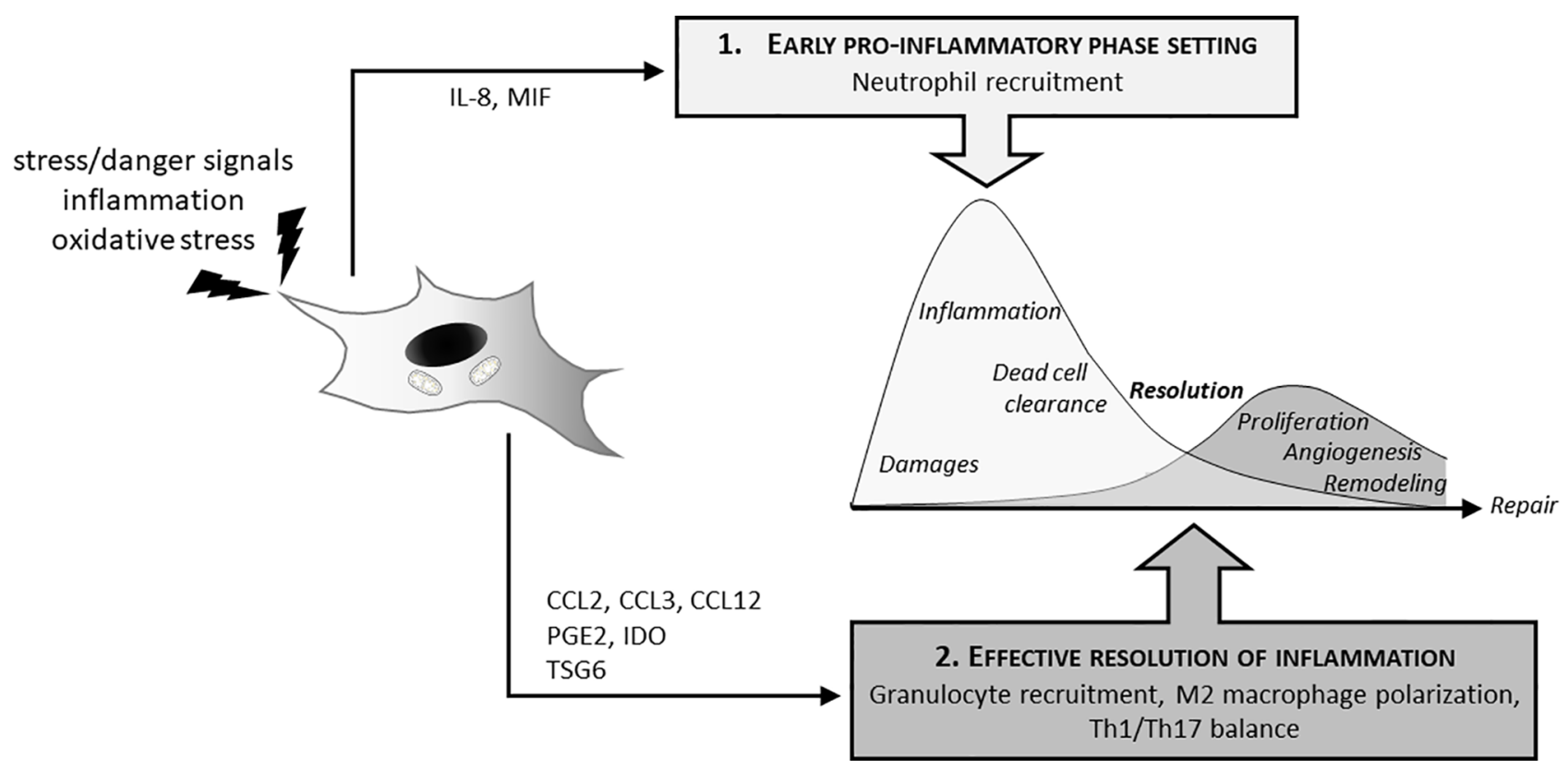

FIGURE 1 | MSCs and inflammatory response: dual effect on induction and resolution of the inflammation. In the initial phase of the inflammatory process, MSCs actively participate to neutrophil attraction (IL8, MIF secretion) for anti-bacterial effect and clearance of tissue debris. This initial phase is required to further promote tissue recovery and repair. MSCs also have decisive effects on the switch from this inflammatory phase to its resolution necessary to initiate tissue reconstruction. MSCs thus favor granulocyte recruitments through cytokines (CCL2, CCL3, CCL12), induce M2 polarization (PGE2, IDO, TSG6) as well as Th1/Th17 balance.

proliferation (47). After phagocytosis of human UC-MSCs by monocytes, phagocytic monocytes acquired a predominantly anti-inflammatory phenotype characterized by increased IL-10 secretion, decreased TNF- $\alpha$ production and expression of M2type receptors such as CD163 and CD206 (48).

MSCs can change the immune response locally but also change the peripheral and systemic response. In a sepsis model in mice, intravenous injected BM-MSCs interact with lung and also circulating monocytes and macrophages and reprogram them through PGE2 production. PGE2 bind to prostaglandin receptor subtype 2 (EP2) and 4 (EP4) on macrophages, producing higher amounts of IL-10. IL-10 seems prevent neutrophils from migrating into tissues limiting organ damage and reducing inflammation (2). Similarly, in an E.coli-induced pneumonia model, the antimicrobial effect of intravenous injected human BM-MSCs is dependent on alveolar macrophages. Indeed, the transfer of mitochondria from MSCs to macrophages, through tunneling nanotube and microvesicles, improves mitochondrial function and metabolism that enhances macrophage phagocytic capacity (49). In an experimental silicosis model, intravenous injection of MSCs-derived exosome containing miRNA or mitochondria suppress inflammation by inhibiting inflammatory monocyte recruitment in the lung. Moreover, MSCs-derived exosomes block TLR signaling in macrophages and therefore the production of inflammatory mediators linked to these pathways that are essential to the inflammatory response (50). The effect of MSCs on systemic inflammation is also true in a pathological context different from those of infection. In the phase I clinical trial ADIPOA, patients with severe knee osteoarthritis (OA) received one single intra-articular injection of autologous ASCs. Results demonstrated that after 3 months, ASCs local injection modulates the distribution of circulating monocyte subset with a significant impact on classical monocyte (51). Moreover, different studies demonstrated that intraarticular injection of MSCs decreases the pain of the patients that can be linked with a decrease of local inflammation $(52,53)$.

\section{MSCS AND IMMUNE CELLS MECHANISMS OF COMMUNICATION TO EXERT IMMUNOMODULATION}

The constant interaction between MSCs and the innate immune system is essential to balance the inflammatory response to maintain and restore tissue homeostasis. Several channel of communication have been described.

\section{Paracrine Secretion}

MSCs-mediated immunomodulation works through a synergy of mechanisms dependent on cell contact and soluble factors. Secretion of Interleukin 1 Receptor Antagonist (IL1-RA) (54) and PGE2 (42) can promote the polarization of macrophages toward the type 2 phenotype. Human ASCs-produced-TSG6 reduce the inflammatory response and improves DSS-induced 
colitis by inducing polarization towards M2 macrophages in mice (55). Similar effects were observed after MSCs treatment of inflammatory diseases such as corneal inflammation (56), acute lung injury (57) and acute peritonitis (58). TSG6 produced by MSCs also inhibits the recruitment of macrophages and inflammatory monocytes in the inflammatory environment (59). Others paracrine factors modulate also monocyte activation state. Indeed, secretion of IL-6 (60) and HGF (61) by MSCs induces the polarization of monocytes toward an alternative phenotype characterized by secretion of high level of IL-10 and low level of IL12 and TNF- $\alpha$. Recent studies demonstrate that MSCs, through synergic secretion of CCL2 and CXCL12, induce M2 polarization of tissue macrophages that are necessary mediators of protective effect on colitis (62).

\section{Direct Cell-Cell Interaction}

Education of innate immune cells by MSCs is also mediated by membrane receptor and cell-cell interactions (63). CD54 is the highest expressed adhesion molecules on MSCs and it expression is increased by inflammatory molecules (64). Several studies demonstrated that CD54 switch macrophage polarization through CD54-LFA-1 interaction. In a mouse co-culture system, Takizawa et al. demonstrated that CD54-LFA1 interaction between MSCs and macrophages promoted the proliferation of M2-macrophages under hypoxic condition (65). Interestingly, unconventional but functional interaction through CD54 between pro-inflammatory classically activates macrophages and BM-MSCs modifies MSCs functions and increases their immunosuppressive capacities (66). Moreover, CD54 ${ }^{\text {high }}$ MSCs increase the survival of mice in a GVHD model by migrating to secondary lymph node where they suppress DCs maturation and Th1-differentiation of CD4+ T cells (67). MSCs also express receptors such as galectins that have been related to the immunosuppressive functions of MSCs. Thus, the galectin 9expressed MSCs modulates T cell functions in particular inhibits their activation but stimulates their apoptosis $(68,69)$. In parallel, the direct effect of galectin 9 expressed by MSCs on the innate immune cells was not investigated. However, several studies demonstrated that galectin 9 promotes the differentiation of macrophages toward an anti-inflammatory profile $(70,71)$. The CD200-CD200R axis represents another specific interaction between MSCs macrophages. CD200 can bind to its receptor, CD200 receptor (CD200R), to suppress the activity of many immune cells, especially macrophages (72). CD200 expressed by human BM-MSCs inhibits the TNF- $\alpha$ secretion from THP-1 differentiated macrophages (73). MSCs also inhibit the differentiation of myeloid precursors through CD200CD200R1 interaction and decrease inflammation and inflammatory cells infiltration in a corneal injury model (74). CD200R is also expressed on the microglia and recent study demonstrated that, in a model of middle cerebral artery occlusion, intravenous-injected BM-MSCs inactivate the microglia in the peri-infarct area via CD200-CD200R signaling pathway and reduce the volume of the infarct zone (75). MSCs can also modulate microglia activation through others receptors such as PDL-1 (76) and CXCL-4.

\section{Extracellular Vesicles (EV) and Exosomes}

MSCs can communicate with nearby cells through secretion of exosomes, small membrane vesicles that contain bioactive molecules like proteins, lipids, mRNAs, microRNAs and mitochondria (69). These molecules can be transferred and reprogram the recipient cells (77). Several studies demonstrated that MSCs, through secretion of exosomes, modify macrophage phenotype and have beneficial effects on inflammatory diseases.

In fact, in an inflammatory bowel diseases model, infusion of MSCs-derived exosomes decreases the severity of acute but also chronic colitis by maintaining intestinal barrier integrity and reducing inflammation by targeting colon macrophages (78-81). Several papers demonstrate that the beneficial effect of MSCsderived exosomes is mainly relied on their effect on macrophages. Indeed, Liu et al. demonstrated that metallothionin-2 containing exosomes are transferred to colon macrophages that polarize into M2 anti-inflammatory phenotype and produce IL-10, key factors of the protective effects of MSCs-derived exosomes $(3,78)$. Moreover, transfer of miR146 through EV-derived MSCs modify also macrophage polarization and attenuate colitis. Indeed, miR146 inhibited TNF receptor-associated factor 6 (TRAF6) and IL-1 receptorassociated kinase 1 (IRAK1) expression, down-regulated phosphorylation of NF-B p65 that decreased pro-inflammatory cytokines production by colon macrophages (80). Transfer of miR146 containing exosome from MSCs to macrophages also protects mice from sepsis by inducing M2 polarization and by decreasing inflammation (82).

Different studies also demonstrated that MSCs-derived exosomes have regenerative properties after myocardic infarction (83), acute skeletal degeneration (84) and cutaneous wound healing $(85,86)$ by decreasing local inflammation and by activating parenchymal cells. In lung inflammatory diseases, MSCs-derived EV protect the lung epithelial cells dependent on miR21-5p transfer, promote the polarization of alveolar macrophages from pro-inflammatory to anti-inflammatory phenotype and decrease the macrophage-driven inflammation (87, 88). The protective effects of MSCs-derived EV or MSCs alone as treatment of lung diseases and specifically acute respiratory distress syndrome (89) make them potential candidates for Covid-19 treatment (90).

Future directions already consider MSCs-EV as an alternative to MSCs cell therapy. To date, compelling evidence for safe, consistent and controlled productions is still needed in addition to proof of efficacy in preclinical studies.

\section{Mitochondria Transfer}

Mitochondria transfer recently appeared as novel intercellular signaling pathways providing danger/rescue signals. Since tunneling nanotubes description as a possible intercellular organelle transport system (91) and the fact that such exchange can rescue aerobic respiration in cells with impaired mitochondria (92), mitochondrial transfer has been considered as an efficient way to enhance cell survival and reprogramming. MSCs are shown to release healthy mitochondria as a pro- 
survival factor. Conversely MSCs can capture mitochondria from damaged cells to set-up adaptive response, both mechanisms acting for cell rescue and tissue recovery $(93,94)$. To date intercellular transfer of mitochondria is a novel mechanism able to restitute bioenergetics in impaired cells with substantial consequences on cell fate and function opening to promising therapeutic potential. The immune and metabolic consequences of such mitochondrial exchanges will be develop later in the review.

\section{Efferocytosis}

Clearance of apoptotic cell by macrophage and dendritic cells, i.e. efferocytosis, is reported to suppress inflammation, mediate immune tolerance and orchestrate tissue homeostasis. Interaction of macrophages with apoptotic cells leads to macrophage reprogramming and induces IL-10, TGF- $\beta$ and PGE2 secretion that further blocks inflammatory mediator production whereas pro-resolutive lipid mediators are produced (such as resolvin and lipoxin) $(95,96)$. During acute inflammation, neutrophils massively undergo apoptosis and their uptake by macrophages reprogram them from inflammatory M1 to pro-resolutive M2 phenotype initiating the resolution phase of the inflammatory process (97). Interestingly MSCs are able to phagocyte apoptotic cells. Phagocytosis of apoptotic cells by MSCs is also reported to participate to immunosuppression through a COX2/PGE2 pathway (98). Another underlying mechanism of action in MSCs immunosuppressive activity involving apoptosis was recently revealed by Akiyama et al. MSCs secrete MCP1 to recruit and to induce $\mathrm{T}$ cell apoptosis via a FAS/FAS ligand pathway. Subsequently apoptotic $\mathrm{T}$ cell phagocytosis by macrophages lead to TGF- $\beta$ secretion causing regulatory T cell upregulation thus resulting in immune tolerance (99).

When MSCs undergo apoptosis, they can be eliminated by macrophages. Galleu et al. demonstrated that MSCs after infusion in a mouse model of GVHD undergo apoptosis through a cytotoxic activity and still exert immunosuppressive activity. Injection of apoptotic MSCs and their phagocytosis by macrophages induce an IDO-dependent immunosuppression $(48,100)$. Such findings bring interesting insight in the explanation of MSCs mechanisms of action in cell therapy. These data support the hypothesis that MSCs do not necessarily have to engraft to bring therapeutic benefit. In this study, it is shown that despite their transient presence after administration, MSCs trigger efficient immunosuppression.

\section{MSCs Perception by the Immune System: From a Privileged to an Elusive Status}

In line with this close and reciprocal interaction with immune cells and their immunomodulatory properties, MSCs have been reported to be "immunoprivileged" suggesting there could be protected against immune detection and rejection when injected in allogenic setting. To date it is considered that MSCs are rather "immunoevasive" meaning weakly immunogenic (101). It means that the inflammatory tissue context influences the balance between immunosuppressive activity and MHC Class II expression by MSCs that drive the immune reactivity leading in either tolerance or rejection after allo-immunization. Nevertheless, and as described above a prolonged persistence of MSCs is not necessarily required for a sustained therapeutic effect. In some pathological situation, a transient presence could be sufficient to guide tissue cell behavior for a long lasting therapeutic benefit $(102,103)$. It thus appears that further data are required to understand how host immune response to allogenic MSCs occur and how it may affect MSCs therapeutic efficacy in acute syndromes as well as chronic diseases. MHC controls, MSCs immunogenicity through appropriate immunomonitoring should bring answers.

\section{MSCs AS A FULL NON-HEMATOPOIETIC IMMUNE CELLS COMPONENT?}

It is admitted that immune functions are however not restricted to hematopoietic cells and also include stromal or structural cells, and MSCs as such, that are able to express a large range of immune regulators and cytokines. It is noticeable that MSCs may also trigger some immune functions by themselves, such as mechanisms against pathogen defense that can, to some extent, be compared to professional phagocytes.

MSCs are currently considered as new possible treatment for infectious diseases link to their antimicrobial activity $(104,105)$. Indeed, INF- $\gamma$ and TLR activated MSCs can improve the antimicrobial activity of certain antibiotics (106) and secrete antimicrobial peptides such as cathelicidin LL-37 (105, 107), human $\beta$-defensin-2 (hBD-2) (108), hepcidin (109), and lipocalin-2 (Lcn2) (110). Different studies demonstrated that untreated MSCs also have an antibacterial activity. Monsarrat et al. showed that ASCs could disturb bacterial division, induce bacterial membrane permeabilization through ROS secretion and phagocyte Gram-positive and Gram-negative bacteria. Moreover, in a mouse model of pathogen-induced periodontitis, engraftment of human ASCs decreases the bacterial load (111). Unstimulated conditioned medium of human BM-MSCs shows an antimicrobial activity as well as an inhibitory effect on biofilm formation of $V$. cholerea (112).

However, the major antibacterial effect of MSCs remains linked to the modulation of the immune system. First, MSCs can produce chemokines such as MIP1 $\alpha$ (macrophage inflammatory protein 1-alpha) and CXCL2, which attracts proinflammatory M1 macrophages that have antimicrobial activities (45, 113). Additionally, MSCs can increase macrophage phagocytosis capacity in vitro and in vivo of mouse alveolar macrophages and human monocyte-derived macrophages linked to the transfer of mitochondria. In a mouse model of E. coliinduced pneumonia, the antimicrobial effect of intravenousinjected MSCs is dependent on alveolar macrophages and on the nanotube and microvesicles-mediated mitochondrial transfer from MSCs to alveolar macrophages (49). Transfer of mRNA through microvesicle from MSCs to macrophages can also modulate antibacterial immune response. Indeed, in an infectious model of acute lung injury, intravenous 
administration MSCs microvesicles 4 hours after the injury reduces the influx of white blood cells and neutrophils and decreases the total protein concentration in the bronchoalveolar lavage fluid at 24h (114).

MSCs can also be efficient as carrier to deliver antibiotics. BM-MSCs are capable to uptake ciprofloxacin and then release active antibiotic up to 24 hours to inhibit bacterial proliferation (115). Several studies demonstrated that MSCs have higher engraftment capacity within sites of inflammation and bacterial infection therefore antibiotic-load MSCs can represent a puissant tool to deliver antibiotics into infected deep tissues. However, to firmly rely on such potential additional in vivo experiments are required.

To move forward, the next provocative question would be can MSCs be considered as macrophage-like cells? This striking question takes its roots in seminal paper describing that preadipocytes/ASCs share numerous features with macrophages such as inflammatory cytokine release and phagocytosis of apoptotic bodies (116) that was also confirmed in human (117). At this time, ASCs were named preadipocytes because MSCs were restricted to bone marrow and were not yet the object of many attentions for their biological roles and the perspectives they may open in regenerative medicine. The close similarity between adipose progenitors and macrophages has been emphasized later (118) and described as related to stemness of cells (119). It is noteworthy that the putative link between adipose progenitors and innate cells is consistent for a phylogenetic point of view with the well-known role of fat body cells in the defense system of insects (120). This striking analogy is also highlighted by the fact that adipose progenitors proliferate upon inflammatory cytokines stimulation (121) and furthermore, can be infected and represent a reservoir for different infectious agents among which HIV, trypanosoma and mycobacterium tuberculosis (122-124). This privileged link with infectious agents could be due to the emerging role of intracellular lipid micro-droplets as assembly platforms for pathogens $(125,126)$. Whereas this literature is essentially based on investigations on adipose tissue and could thus be considered specific to ASCs for their commitment towards adipocyte lineage, recent publications show that such conclusions can be extended to MSCs (127). Recent multi-omics comprehensive profiling brought strong arguments to consider such stromal cells as key players in the immune system (128). An extensive characterization in twelve organs in mice is proposing that structural cells, i.e. epithelial, endothelia and fibroblast cells largely regulate immune genes transcription and epigenetic regulation upon infection and may thus be considered as an integral part of the immune system, together with hematopoietic cells (128). Although the term of MSCs is not used the close relationship between MSCs and fibroblast including in cancer context (129), this work largely claims a direct role of MSCs in immunity as active immune agents and not only as a partners of classic hematopoietic immune cells.

Finally, the analogy of MSCs with macrophages extends to their phenotypic polarization as inflammatory cytokines such as
INF- $\gamma$, TNF- $\alpha$ or TLR3 stimulation primes MSCs into an antiinflammatory and immunosuppressive MSC-2 phenotype (secreting IDO, NO, PGE2, TGF- $\beta$ ) whereas TLR4 activation rather induces a pro-inflammatory MSC-1 phenotype (producing MIP-1 $\alpha$, MIP-1 $\beta$, RANTES, CXCL9, CXCL10) (130, 131).

\section{METABOLIC COUPLING OF MSCs WITH IMMUNE CELLS AND FUNCTIONS}

Cellular metabolism supports all tissue functions ensuring on demand energy supply required for cell activity. Additionally, nutrient-derived metabolites are important mediators of cellular metabolic fluxes and signaling. Both immune and metabolic functions are regulated by common pathways that act in concert when sensing tissue threats to provide a coherent adaptive response converging organism resources towards an appropriate energy production for vital functions such as tissue defense and regeneration. Inflammatory signaling factors (i.e. cytokines, lipid mediators, amino acid-derived metabolites, pathogen-mediated signals, tissue danger signals) and hypoxia can orientate metabolic pathways in various cells other than immune cells, adipocytes, hepatocytes, neurons and MSCs for example.

\section{Intracellular Metabolism Drives Fate and Functions in MSCs and Immune Cells}

Immunometabolism classically refers to immune cells metabolism that governs their fate and function. It is greatly documented how cellular metabolic fluxes and metabolite detection dictate the immune response developed by macrophages, dendritic cells, neutrophils and lymphocytes (132-134). It is now admitted that macrophages polarization is connected to metabolic pathways with an activation of glycolytic pathways in inflammatory M1 macrophages whereas M2 macrophages use fatty acid oxidation and mitochondrial oxidative phosphorylation system (OXPHOS) reactions to generate ATP $(135,136)$. It is reported that metabolic reprogramming can operate in immune cells as a result of tissue factor detection and oxygen availability. Oxygen deprivation, similarly to LPS exposure, induce an increase in HIF- $1 \alpha$ associated with a glycolytic pathway activation leading to a M1 polarization. In M1 macrophage where glycolytic pathway dominates, mitochondrial ROS production also increases (via succinate accumulation and oxidation) thus sustaining the inflammatory status (137). Conversely an increase in PHD2 activity, as observed under physioxic condition, or an increase in HIF- $2 \alpha$ are associated with a switch towards a M2 phenotype and an elevated fatty acid oxidation and mitochondrial respiratory chain activity (138). Such striking impact of metabolism is not only true for innate but also for adaptive immune cells and can largely be extended to MSCs. Metabolic fitness of MSCs in response to environmental signals regulates their immunomodulatory properties suggesting that immunometabolism also applies to MSCs. 


\section{Metabolism at the Heart of MSCs and Immune Cells Crosstalk}

Evidences of direct metabolic coupling between MSCs and immune cells are poorly documented. It is just demonstrated that human MSCs induce the acquisition of M2 macrophage phenotype through a lactate-mediated metabolic reprogramming (139). Reciprocal metabolic reprogramming is more described between stromal and cancer cells. It is largely described how cancer cells hijack stromal cells activity to develop metabolic adaptive strategies based on oxidative stress handling, to favor tumor promotion $(140,141)$.

Indirect coupling evidences are more obvious in the literature. MSCs are sensitive to micro-environment changes appearing with tissue dysfunction and can operate metabolic switch and functional adaptations in their biology that in turn will impact the immune response and inflammatory status. Modulation of the redox environment and oxidative stress resulting from free radical accumulation (reactive oxygen species, ROS and reactive nitrogen species, RNS), $\mathrm{pH}$, oxygen tension and nutrient gradient perturbations are associated with cell injury, organ failure and the aging process $(142,143)$. MSCs are quite resistant to oxidative stress and react by developing strong enzymatic (superoxide dismutases, glutathion peroxidase, catalase, sirtuins, heme oxidase-1) (144-147) and nonenzymatic (reduced glutathione, HIF-1 $\alpha$, Heat Shock Proteins, nuclear factors) (148-150) scavenging, anti-oxidant and cytoprotective defenses. These activities that modulate redox status are concomitant with the immunomodulatory effect of MSCs; some being required as demonstrated with depletion/ deletion, overexpression approaches $(145,151,152)$ or preconditioning strategies $(86,153-157)$, some being induced downstream of immune pathways (158).

Mitochondria thus appears to play a pivotal role in immune cell metabolic reprogramming ensuring, as a signaling hub, the adequate crosstalk between immunity control and cellular energy providing $(137,159-162)$. To that end, mitochondria transfer is under investigation. Mitochondrial exchange may occur through tunneling nanotubes, microvesicle capitation, cell junction, cell fusion or direct uptake $(93,94)$. MSCs can donate healthy mitochondria to damaged cells rescuing aerobic respiration in cells with mitochondrial genetic defect (92) and reprogramming and restoring bioenergetics needs of injured cells in various disorders such as brain stroke, ischemic heart, lung, kidney and degenerative diseases (163-166). Mitochondrial translocation from MSCs to immune cells can trigger immunomodulatory mechanisms. Mitochondria transfer from MSCs to macrophages enhance phagocytosis and antiinflammatory phenotype $(49,167)$. The uptake of MSCs mitochondria by $\mathrm{T}$ helper 17 cells promote their acquisition of anti-inflammatory phenotype and their metabolic reprogramming towards OXPHOS reactions (168). According to such findings mitochondria transfer from MSCs mediates tissue repair and regeneration and take part in their therapeutic potential. It is noteworthy that bidirectional mitochondrial exchange can operate. When damaged or stressed, cells release and convey mitochondria to MSCs and it is shown to activate anti-apoptotic function and mitochondrial biogenesis in MSCs (169). MSCs exposure to mitochondria from damaged cells that confer cytoprotective and pro-regenerative properties may be a way to precondition MSCs for an enhanced and targeted therapeutic efficacy. Nevertheless, the mechanisms of mitochondrial transfer through GAP junctions, nanotubes, uptake, cell fusion or micro-vesicles, as well as the frequency, the efficacy and the donor cells have to be further explored to give rise to therapeutic approaches using mitochondrial transplantation (93). In addition, mitochondrial transfer has to be manipulated with caution due to dual effects of metabolic switch that may promote repair but cancer as well (170).

It was recently reported that liver tumor cell growth was associated with mitochondrial fusion causing an increase in oxygen consumption and ATP production (171). The possibility that metabolic status can be inferred from mitochondrial morphology opens to numerous perspectives in MSCs therapy. Indeed, mitochondria functions are intimately linked to their morphology, where fission causing mitochondria fragmentation is associated with metabolic dysfunction whereas fusion generating a functional network is acting to preserve and protect cell integrity. In MSCs, mitochondrial dynamics is already known to be involved in metabolic changes and senescence favoring tissue recovery and regeneration (172, 173). Additional studies are still necessary to confirm a causative relationship between MSCs activity and mitochondria morphological changes.

Other metabolic pathways in MSCs immunomodulatory activity relies on enzymes degrading amino acids and producing metabolites that may boost or dampen immune responses. Tryptophan is an essential amino acid catabolized through the kynurenine pathway by the rate-limited enzyme indoleamine 2,3-dioxygenase (IDO). In MSCs the activation of IDO in response to inflammatory factors is triggering immunosuppression as a result of tryptophan depletion causing apoptosis of $\mathrm{T}$ cells, inhibition of $\mathrm{T}$ cells and NK cells proliferation, inhibition of DCs maturation, and induction of Treg immune suppressor cells (174). On the other hand, tryptophan metabolites from the tryptophan hydroxylase (TPH) pathway (5-methoxytryptophan, melatonin) protect MSCs against replicative and oxidative stress-induced senescence (175). The amino acid arginine is catalyzed by enzymes highly regulated by the inflammatory setting leading to opposite immunological consequences in myeloid cells. Indeed, in inflammatory M1 macrophages arginine is catabolized by nitric oxide synthases (NOS) into NO and citrulline. While in wound healing M2 macrophages, arginine is rather metabolized by arginases generating ornithine, urea, polyamine and proline (176). Whether such decisional amino acid-dependent metabolic switch exists in MSCs is not known and has to be explored.

Finally, mesenchymal and immune cells that both act as sensor and actor of tissue integrity, are tightly connected entities where their respective metabolic and functional activities result and influence each other. They both constantly integrate environmental signals and communicate for a 
concerted and efficient metabolic reset to properly fuel functional adaptations of the immune response (Figure 2).

Ultimately, immunometabolism has to be investigated at the whole organism level considering its generalized high impact effect in homeostasis as well as pathogenesis and aged-related chronic diseases (132). Systemic immunometabolism exploration and control, possibly through targeting MSCs activity, represent the current challenge to develop integrated and holistic approaches for regenerative medicine strategies.

\section{CHALLENGES AND OPPORTUNITIES FOR FUTURE THERAPEUTIC APPLICATIONS}

Many unsolved questions remain to overcome present limitations to reach sustain and significant efficacy that is not yet achieve in late-phase clinical trials. The translation of MSCs into clinic is more difficult than expected. Indeed, the cell therapy outcome is not solely depending on ATMP properties but also conditioned by the route of delivery. This major issue is currently questioned and must be considered as an adaptable option to fit with the multiple possible applications (177). Intravenous infusion of MSCs is the most common way due to the convenience and limited risk, and remains appropriated when systemic effects are expected. However, several groups demonstrated that intravenous-injected MSCs are trapped in the lung and persist less than 3 days in the tissue $(178,179)$ whereas local application or injection in the targeted tissue seems to increase engraftment. Intramuscular-delivered human MSCs in mouse models survived for up to 5 months after injection (180). In a comparative study, Giri et al. observed that extravascular injection of MSCs improves colitis while the intravenous injection at maximal dose does not (181) suggesting that cell delivery is a critical issue for therapeutic efficacy. Satisfactory solutions may arise from recent developments that associate cells with smart materials, bioprinted scaffolds or organoids allowing 3D structuration opening to alternative approaches for tissue filling, replacement and topic applications, with the advantage of including the biomechanical component required for guiding an optimal tissue reconstruction. Whether MSCs need to integrate the targeted tissue, are intended to be progressively replaced native tissue cells or have to rapidly undergo apoptosis for optimal therapeutic benefit is not resolved. Such apparent contradictions have to be addressed and certainly reveals the existence of multiple pathology-dependent mechanisms of action that may ultimately lead to the same outcome.

Besides, in order to succeed in prompting MSCs therapy into suitable clinical practices, the current major challenges reside in (i) MSCs manufacturing towards standardized and optimized culture processes, (ii) improving the MSCs characterization including multiscale and multiparametric analyses, (iii) developing dynamic potency tests to qualify MSCs batches that bring guaranties of their therapeutic potential, (iv) identifying

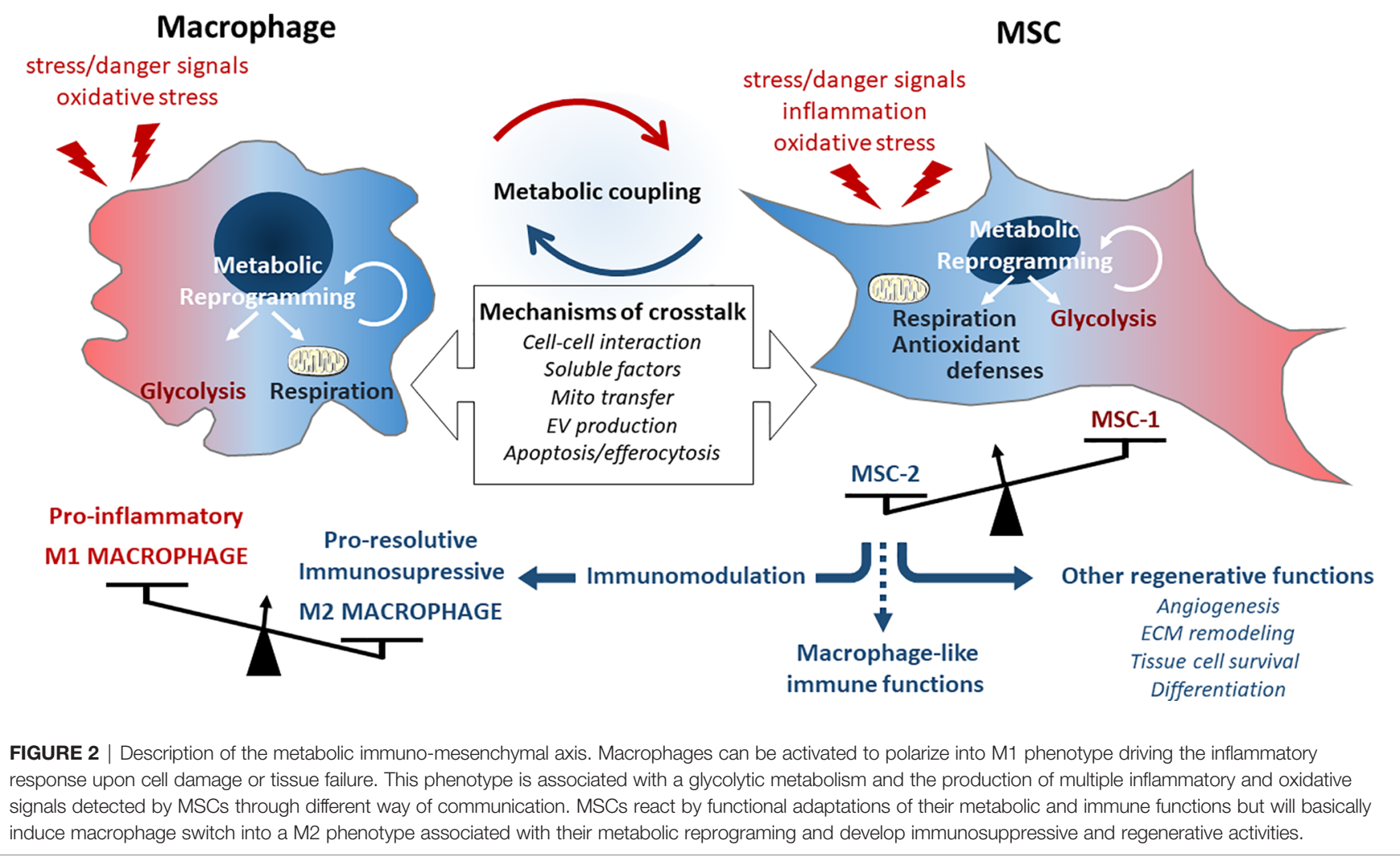


from completed trials MSCs parameters correlated with clinical benefit in order to propose predictive markers for a given physiopathologic background. The study of MSCs biology over the last decade underlines that beyond their intrinsic potential (availability, tissue specificity (182), individual features from global multi-omic and phenotyping signatures) we have to estimate, for clinical purpose, their wide range of responses when facing a challenge. Their tissue function and therapeutic benefit indeed reside in this unique ability to map environmental cues, orchestrate local reactions with possible systemic consequences such as immunometabolism reprogramming.

Bio-production and bio-banking processes for clinical purpose impose environmental conditions that can change or alter biological properties of MSCs and therefore have to be carefully establish to not compromise their therapeutic potential. Most of the clinical trials used cryopreserved MSCs that were defrosted and immediately infused to patients. However, numerous studies demonstrated that MSCs immediately postthaw have less immunomodulatory capacity in vitro $(183,184)$. They are more susceptible to $\mathrm{T}$ cell-mediated lysis as well as instant blood mediated inflammatory reaction $(178,185)$ that can explain the low persistence of cryopreserved-MSCs after injection. Interestingly, a culture step prior the implantation rescues post-thaw deleterious effects, reverses cryoinjurious effects $(186,187)$ and increases the engraftment of the cells in tissue (180).

Confirming the importance of such considerations, it can be noticed that the only MSCs-based ATMP approved by the European Medicines Agency is Alofisel ${ }^{\circledR}$ to treat Crohn disease. The indication is the use allogenic ASCs cultured prior the implantation and locally administrated into the anal fistula $(188,189)$. Cell therapy procedure is thus validated as a combination of a pharmaceutical cell product, a production process and a mode of delivery all driven by the specificity of the pathological context to be treated.

MSCs qualification is the next step to improve. Dynamic tests exploring their plasticity (stimulate/inhibit a function) (190, 191), flexibility/stiffness (amplitude in resistance and response to stress) and decisional metabolic switches should be more predictive regarding to therapeutic expectations. Such functional characterization may also influence the bio-production process for MSCs and methods to acquire, preserve and/or enhance the expected potency after administration. Optimized cell production can be reached through MSCs preconditioning or licensing (transient hypoxia, cytokines priming, nutrients stress before administration) or at least may define the most appropriate therapeutic window for MSCs therapy (192197).All these datasets integrating and combining multiparametric individual characteristics with therapeutic potential assessed in vitro will allow to correlate single-cell signatures with collective response to a challenge at the cell population level to define bioengineered MSCs product fitness. Computational analysis including principal component analysis, correlation, clustering analyses together with Machine Learning methods should help to resolve the question of cell heterogeneity and functional potency to propose customized productions.
A next critical issue resides in being able to select the most permissive cell product for personalized therapeutics benefit according to patient characteristics. Indeed, extensive analyses of MSCs properties in vitro is not sufficient to predict their efficacy in patient. Retrospectives analyses of clinical outcomes and recovery in cohorts of patients receiving allogenic MSCs should allow to identify specific markers or signature associated with MSCs treatment benefit. Such approaches should help to address the question of responder and non-responder identification. Based on clinical trial data and MSCs testing in vitro, Artificial Intelligence and Deep Learning models could be trained to predict therapeutic MSCs efficacy in a given pathologic background.

\section{Aging Effects on MSCs Properties}

With aging the complex and dynamic networks involving native MSCs activity may gradually deteriorate due to alteration accumulation in MSCs and/or modification of their surrounding environment. Declines that progressively operate may at some point exceed MSCs resilience capacity and ultimately compromise tissue homeostasis and functional integrity $(198,199)$. With aging changes in individual features of MSCs are observed such as a decrease in number, in differentiation potential, in proliferation rate, in redox control, some mitochondrial dysfunctions and modifications of their secretory repertoire associated with a senescent phenotype (200-202). MSCs age-related dysfunction may alter MSCs/ immune cells dialogue and lead to a loss in their immunomodulatory activity and therefore negatively impact therapeutic outcomes in cell therapy (203-206). The question of MSCs senescence and resilience is not sufficiently addressed until now and should be implemented to the required safety control performed to release suitable MSCs for clinical use. Another critical point would be to delineate the putative involvement of MSCs as a niche component in the reported progressive deviation of the hematopoiesis towards myeloid versus lymphoid lineage presaged as causative in the emergence of inflammaging (207). To some extend MSCs aging and associated functional consequences have to assess independently of the age of the donor for therapeutic use.

\section{Opening to Allogenic MSCs Therapy for Metabolic and Inflammatory Age- Related Diseases}

The risk for developing a wide range of chronic disorders rises with aging and represent a growing public health issue with the increased lifespan of the population. The geroscience approach aims to prevent, delay and possibly reverse the occurrence or the severity of age-associated chronic pathologies by acting on key molecular, cellular and systemic aging processes. Allogenic MSCs from healthy donors thus appear as a promising candidate due to their pleiotropic effects to offer new options to treat age-related disorders associated with chronic inflammation. MSCs therapy trials in the elderly already showed benefits in osteoarthritis (208, 209), periodontitis (210), type 2 diabetes (211) or neurodegenerative diseases $(212,213)$ for example. Recently 
allogenic MSCs therapy was tested in aging frailty showing promising results displayed by a decrease in inflammatory status and an improvement in physical performance over a 6 months follow-up (214). Ongoing trials outcomes are however required to confirm those preliminary achievements.

\section{CONCLUSION}

Supported by recent single cell RNA sequencing in mouse, resident immune and stromal cells organize into a cross-tissue cellular network. Together with endothelial and dendritic cells they represent the recurrent components contributing and defining each tissue micro-environment, highlighting their crucial role in local response that can extend to the systemic level (215). Stromal cells and resident immune cells belong to the connective tissue present in all organs allowing them to display a specific and adapted tissue-dependent activity as well as to integrate and modulate systemic response at the organism scale through an interconnected and dynamic network. Metabolic reprogramming is a way to shuttle signals and factors in this privileged bidirectional dialogue.

To conclude, where the reductionist approach consisting in managing each disease independently have proved to be ineffective in the treatment of age-related pathologies, allogenic MSCs therapy can be proposed as an alternative solution for patients elected through reliable criteria. Inflammation and metabolism can be considered as biological rheostat able to reset the entire system and MSCs as a determinant regulator of both functions towards homeostasis restoration. Based on relevant selection criteria and optimized production process,

\section{REFERENCES}

1. Ringden O, Uzunel M, Rasmusson I, Remberger M, Sundberg B, Lonnies H, et al. Mesenchymal Stem Cells for Treatment of Therapy-Resistant GraftVersus-Host Disease. Transplantation (2006) 81:1390-7. doi: 10.1097/ 01.tp.0000214462.63943.14

2. Nemeth K, Leelahavanichkul A, Yuen PS, Mayer B, Parmelee A, Doi K, et al. Bone Marrow Stromal Cells Attenuate Sepsis Via Prostaglandin E(2)dependent Reprogramming of Host Macrophages to Increase Their interleukin-10 Production. Nat Med (2009) 15:42-9. doi: 10.1038/nm.1905

3. Liu H, Liang Z, Wang F, Zhou C, Zheng X, Hu T, et al. Exosomes From Mesenchymal Stromal Cells Reduce Murine Colonic Inflammation Via a Macrophage-Dependent Mechanism. JCI Insight (2019) 4(24):e(131273) doi: 10.1172/jci.insight.131273

4. Mao F, Tu Q, Wang L, Chu F, Li X, Li HS, et al. Mesenchymal Stem Cells and Their Therapeutic Applications in Inflammatory Bowel Disease. Oncotarget (2017) 8:38008-21. doi: 10.18632/oncotarget.16682

5. Ringden O, Nilsson B. Death by Graft-Versus-Host Disease Associated With HLA Mismatch, High Recipient Age, Low Marrow Cell Dose, and Splenectomy. Transplantation (1985) 40:39-44. doi: 10.1097/00007890198507000-00009

6. Noort WA, Kruisselbrink AB, in't Anker PS, Kruger M, Van Bezooijen RL, De Paus RA, et al. Kruger MMesenchymal Stem Cells Promote Engraftment of Human Umbilical Cord Blood-Derived CD34(+) Cells in NOD/SCID Mice. Exp Hematol (2002) 30:870-8. doi: 10.1016/s0301-472x(02)00820-2

7. Le Blanc K, Frassoni F, Ball L, Locatelli F, Roelofs H, Lewis I, et al. Mesenchymal Stem Cells for Treatment of Steroid-Resistant, Severe, Acute Graft-Versus-Host Disease: A Phase II Study. Lancet (2008) 371:1579-86. doi: 10.1016/S0140-6736(08)60690-X allogenic MSCs position as multimodal tools able to take in charge biological functions interfacing with all organs. Allogenic MSCs therapy by targeting inflammaging and metabolism-aging thus appears in line with geroscience perspectives (216) and is a major challenge to address for the upcoming regenerative and rejuvenative medicine strategies.

\section{AUTHOR CONTRIBUTIONS}

$\mathrm{VB}$ and $\mathrm{AV}$ conceived the main conceptual ideas and structure of the review. VB, AV and LC wrote the manuscript, analyzed and sorted the literature, revised and provided critical feedback on the manuscript. VB provided funding. All authors contributed to the article and approved the submitted version.

\section{ACKNOWLEDGMENTS}

We gratefully acknowledge funding support from the Region Occitanie/Pyrénées-Méditerranée that granted the Inspire Program (Reference no:1901175), the "Fondation des Gueules Cassées” (no.197-2019) and by the European Union's Horizon 2020 Program, ADIPOA2 project, under the grant agreement no:643809. This work was also supported by governmental funding managed by the Agence Nationale de la Recherche for the program "Investissements d'avenir" (ANR-11-INBS-0005) supporting the National Infrastructure ECellFRANCE "Development of a national adult mesenchymal stem cell based therapy platform”.

8. Kurtzberg J, Abdel-Azim H, Carpenter P, Chaudhury S, Horn B, Mahadeo K, et al. A Phase 3, Single-Arm, Prospective Study of Remestemcel-L, Ex Vivo Culture-Expanded Adult Human Mesenchymal Stromal Cells for the Treatment of Pediatric Patients Who Failed to Respond to Steroid Treatment for Acute Graft-versusHost Disease. Biol Blood Marrow Transplant (2020) 26:845-54. doi: 10.1016/j.bbmt.2020.01.018

9. Kebriaei P, Hayes J, Daly A, Uberti J, Marks DI, Soiffer R, et al. A Phase 3 Randomized Study of Remestemcel-L Versus Placebo Added to Second-Line Therapy in Patients With Steroid-Refractory Acute Graft-versus-Host Disease. Biol Blood Marrow Transplant (2020) 26:835-44. doi: 10.1016/ j.bbmt.2019.08.029

10. Kurtzberg J. To Match or Not to Match in Cord Blood Transplantation: A Modern Look At a Recurring Question. Biol Blood Marrow Transplant (2016) 22:398-9. doi: 10.1016/j.bbmt.2016.01.020

11. Fisher SA, Cutler A, Doree C, Brunskill SJ, Stanworth SJ, Navarrete C, et al. Mesenchymal Stromal Cells as Treatment or Prophylaxis for Acute or Chronic Graft-Versus-Host Disease in Haematopoietic Stem Cell Transplant (HSCT) Recipients With a Haematological Condition. Cochrane Database Syst Rev (2019) 1:CD009768. doi: 10.1002/ 14651858.CD009768.pub2

12. Zhao L, Chen S, Yang P, Cao H, Li L. The Role of Mesenchymal Stem Cells in Hematopoietic Stem Cell Transplantation: Prevention and Treatment of Graft-Versus-Host Disease. Stem Cell Res Ther (2019) 10:182. doi: 10.1186/ s13287-019-1287-9

13. Aggeletopoulou I, Assimakopoulos SF, Konstantakis C, Triantos C. Interleukin 12/Interleukin 23 Pathway: Biological Basis and Therapeutic Effect in Patients With Crohn's Disease. World J Gastroenterol (2018) 24:4093-103. doi: 10.3748/wjg.v24.i36.4093 
14. Abraham C, Dulai PS, Vermeire S, Sandborn WJ. Lessons Learned From Trials Targeting Cytokine Pathways in Patients With Inflammatory Bowel Diseases. Gastroenterology (2017) 152:374-388 e374. doi: 10.1053/ j.gastro.2016.10.018

15. Gonzalez MA, Gonzalez-Rey E, Rico L, Buscher D, Delgado M. AdiposeDerived Mesenchymal Stem Cells Alleviate Experimental Colitis by Inhibiting Inflammatory and Autoimmune Responses. Gastroenterology (2009) 136:978-89. doi: 10.1053/j.gastro.2008.11.041

16. Parekkadan B, Upadhyay R, Dunham J, Iwamoto Y, Mizoguchi E, Mizoguchi A, et al. Bone Marrow Stromal Cell Transplants Prevent Experimental Enterocolitis and Require Host CD11b+ Splenocytes. Gastroenterology (2011) 140:966-75. doi: 10.1053/j.gastro.2010.10.013

17. Molendijk I, Bonsing BA, Roelofs H, Peeters KC, Wasser MN, Dijkstra G, et al. Allogeneic Bone Marrow-Derived Mesenchymal Stromal Cells Promote Healing of Refractory Perianal Fistulas in Patients With Crohn's Disease. Gastroenterology (2015) 149:918-927 e916. doi: 10.1053/ j.gastro.2015.06.014

18. Panes J, Garcia-Olmo D, Van Assche G, Colombel JF, Reinisch W, Baumgart DC, et al. Expanded Allogeneic Adipose-Derived Mesenchymal Stem Cells (Cx601) for Complex Perianal Fistulas in Crohn's Disease: A Phase 3 Randomised, Double-Blind Controlled Trial. Lancet (2016) 388:1281-90. doi: 10.1016/S0140-6736(16)31203-X

19. Herreros MD, Garcia-Arranz M, Guadalajara H, De-La-Quintana P, GarciaOlmo D, Group FC. Autologous Expanded Adipose-Derived Stem Cells for the Treatment of Complex Cryptoglandular Perianal Fistulas: A Phase III Randomized Clinical Trial (FATT 1: Fistula Advanced Therapy Trial 1) and Long-Term Evaluation. Dis Colon Rectum (2012) 55:762-72. doi: 10.1097/ DCR.0b013e318255364a

20. Shi X, Chen Q. and Wang F Mesenchymal Stem Cells for the Treatment of Ulcerative Colitis: A Systematic Review and Meta-Analysis of Experimental and Clinical Studies. Stem Cell Res Ther (2019) 10:266. doi: 10.1186/s13287019-1336-4

21. Laroye C, Gibot S, Reppel L. And Bensoussan D Concise Review: Mesenchymal Stromal/Stem Cells: A New Treatment for Sepsis and Septic Shock? Stem Cells (2017) 35:2331-9. doi: 10.1002/stem.2695

22. Lalu MM, Sullivan KJ, Mei SH, Moher D, Straus A, Fergusson DA, et al. Evaluating Mesenchymal Stem Cell Therapy for Sepsis With Preclinical Meta-Analyses Prior to Initiating a First-in-Human Trial. Elife (2016) 5: e17850. doi: 10.7554/eLife. 17850

23. McIntyre LA, Stewart DJ, Mei SHJ, Courtman D, Watpool I, Granton J, et al. Cellular Immunotherapy for Septic Shock. A Phase I Clinical Trial. Am J Respir Crit Care Med (2018) 197:337-47. doi: 10.1164/rccm.201705-1006OC

24. Perlee D, van Vught LA, Scicluna BP, Maag A, Lutter R, Kemper EM, et al. Intravenous Infusion of Human Adipose Mesenchymal Stem Cells Modifies the Host Response to Lipopolysaccharide in Humans: A Randomized, Single-Blind, Parallel Group, Placebo Controlled Trial. Stem Cells (2018) 36:1778-88. doi: 10.1002/stem.2891

25. Wilson JG, Liu KD, Zhuo H, Caballero L, McMillan M, Fang X, et al. Mesenchymal Stem (Stromal) Cells for Treatment of ARDS: A Phase 1 Clinical Trial. Lancet Respir Med (2015) 3:24-32. doi: 10.1016/S2213-2600 (14)70291-7

26. Galstyan GM, Makarova PM. and Parovichnikova En Use of Mesenchymal Stromal Stem Cells for the Treatment of Sepsis. Anesteziol Reanimatol (2015) 60:59-65.

27. Schlosser K, Wang JP, Dos Santos C, Walley KR, Marshall J, Fergusson DA, et al. Effects of Mesenchymal Stem Cell Treatment on Systemic Cytokine Levels in a Phase 1 Dose Escalation Safety Trial of Septic Shock Patients. Crit Care Med (2019) 47:918-25. doi: 10.1097/CCM.0000000000003657

28. Zheng G, Huang L, Tong H, Shu Q, Hu Y, Ge M, et al. Treatment of Acute Respiratory Distress Syndrome With Allogeneic Adipose-Derived Mesenchymal Stem Cells: A Randomized, Placebo-Controlled Pilot Study. Respir Res (2014) 15:39. doi: 10.1186/1465-9921-15-39

29. Matthay MA, Calfee CS, Zhuo H, Thompson BT, Wilson JG, Levitt JE, et al. Treatment With Allogeneic Mesenchymal Stromal Cells for Moderate to Severe Acute Respiratory Distress Syndrome (START Study): A Randomised Phase 2a Safety Trial. Lancet Respir Med (2019) 7:154-62. doi: 10.1016/ S2213-2600(18)30418-1
30. Chen J, Hu C, Chen L, Tang L, Zhu Y, Xu X, et al. Clinical Study of Mesenchymal Stem Cell Treating Acute Respiratory Distress Syndrome Induced by Epidemic Influenza A (H7N9) Infection, a Hint for COVID19 Treatment. Eng (Beijing) (2020) 6(10):1153-61. doi: 10.1016/ j.eng.2020.02.006

31. Saldanha-Araujo F, Melgaco Garcez E, Silva-Carvalho AE, Carvalho JL. Mesenchymal Stem Cells: A New Piece in the Puzzle of COVID-19 Treatment. Front Immunol (2020) 11:1563. doi: 10.3389/fimmu.2020.01563

32. Cao W, Cao K, Cao J, Wang Y, Shi Y. Mesenchymal Stem Cells and Adaptive Immune Responses. Immunol Lett (2015) 168:147-53. doi: 10.1016/ j.imlet.2015.06.003

33. Brandau S, Jakob M, Hemeda H, Bruderek K, Janeschik S, Bootz F, et al. Tissue-Resident Mesenchymal Stem Cells Attract Peripheral Blood Neutrophils and Enhance Their Inflammatory Activity in Response to Microbial Challenge. J Leukoc Biol (2010) 88:1005-15. doi: 10.1189/ jlb.0410207

34. Cassatella MA, Mosna F, Micheletti A, Lisi V, Tamassia N, Cont C, et al. Toll-Like receptor-3-activated Human Mesenchymal Stromal Cells Significantly Prolong the Survival and Function of Neutrophils. Stem Cells (2011) 29:1001-11. doi: 10.1002/stem.651

35. Mahmoudi M, Taghavi-Farahabadi M, Namaki S, Baghaei K, Rayzan E, Rezaei N, et al. Exosomes Derived From Mesenchymal Stem Cells Improved Function and Survival of Neutrophils From Severe Congenital Neutropenia Patients In Vitro. Hum Immunol (2019) 80:990-8. doi: 10.1016/ j.humimm.2019.10.006

36. Mahmoudi M, Taghavi-Farahabadi M, Rezaei N, Hashemi SM. Comparison of the Effects of Adipose Tissue Mesenchymal Stromal Cell-Derived Exosomes With Conditioned Media on Neutrophil Function and Apoptosis. Int Immunopharmacol (2019) 74:105689. doi: 10.1016/ j.intimp.2019.105689

37. Hsu SC, Wang LT, Yao CL, Lai HY, Chan KY, Liu BS, et al. Mesenchymal Stem Cells Promote Neutrophil Activation by Inducing IL-17 Production in CD4+ Cd45ro+ T Cells. Immunobiology (2013) 218:90-5. doi: 10.1016/ j.imbio.2012.02.007

38. Kim J, Hematti P. Mesenchymal Stem Cell-Educated Macrophages: A Novel Type of Alternatively Activated Macrophages. Exp Hematol (2009) 37:144553. doi: 10.1016/j.exphem.2009.09.004

39. Kalinski P. Regulation of Immune Responses by Prostaglandin E2. J Immunol (2012) 188:21-8. doi: 10.4049/jimmunol.1101029

40. Kawahara K, Hohjoh H, Inazumi T, Tsuchiya S, Sugimoto Y. Prostaglandin E2-induced Inflammation: Relevance of Prostaglandin E Receptors. Biochim Biophys Acta (2015) 1851:414-21. doi: 10.1016/j.bbalip.2014.07.008

41. Loynes CA, Lee JA, Robertson AL, Steel MJ, Ellett F, Feng Y, et al. PGE2 Production At Sites of Tissue Injury Promotes an Anti-Inflammatory Neutrophil Phenotype and Determines the Outcome of Inflammation Resolution In Vivo. Sci Adv (2018) 4:eaar8320. doi: 10.1126/sciadv.aar8320

42. Maggini J, Mirkin G, Bognanni I, Holmberg J, Piazzon IM, Nepomnaschy I, et al. Mouse Bone Marrow-Derived Mesenchymal Stromal Cells Turn Activated Macrophages Into a Regulatory-Like Profile. PloS One (2010) 5: e9252. doi: 10.1371/journal.pone.0009252

43. Choi H, Lee RH, Bazhanov N, Oh JY, Prockop DJ. Anti-inflammatory Protein TSG-6 Secreted by Activated MSCs Attenuates Zymosan-Induced Mouse Peritonitis by Decreasing TLR2/NF-kappaB Signaling in Resident Macrophages. Blood (2011) 118:330-8. doi: 10.1182/blood-2010-12-327353

44. Prockop DJ, Oh JY. Mesenchymal Stem/Stromal Cells (Mscs): Role as Guardians of Inflammation. Mol Ther (2012) 20:14-20. doi: 10.1038/ $\mathrm{mt} .2011 .211$

45. Chen L, Tredget EE, Wu PY, Wu Y. Paracrine Factors of Mesenchymal Stem Cells Recruit Macrophages and Endothelial Lineage Cells and Enhance Wound Healing. PloS One (2008) 3:e1886. doi: 10.1371/ journal.pone.0001886

46. Chiossone L, Conte R, Spaggiari GM, Serra M, Romei C, Bellora F, et al. Mesenchymal Stromal Cells Induce Peculiar Alternatively Activated Macrophages Capable of Dampening Both Innate and Adaptive Immune Responses. Stem Cells (2016) 34:1909-21. doi: 10.1002/stem.2369

47. Maqbool M, Algraittee SJR, Boroojerdi MH, Sarmadi VH, John CM, Vidyadaran S, et al. Human Mesenchymal Stem Cells Inhibit the 
Differentiation and Effector Functions of Monocytes. Innate Immun (2020) 26:424-34. doi: 10.1177/1753425919899132

48. de Witte SFH, Luk F, Sierra Parraga JM, Gargesha M, Merino A, Korevaar SS, et al. Immunomodulation By Therapeutic Mesenchymal Stromal Cells (Msc) Is Triggered Through Phagocytosis of MSC by Monocytic Cells. Stem Cells (2018) 36:602-15. doi: 10.1002/stem.2779

49. Jackson MV, Morrison TJ, Doherty DF, McAuley DF, Matthay MA, Kissenpfennig A, et al. Mitochondrial Transfer Via Tunneling Nanotubes is an Important Mechanism by Which Mesenchymal Stem Cells Enhance Macrophage Phagocytosis in the In Vitro and In Vivo Models of ARDS. Stem Cells (2016) 34:2210-23. doi: 10.1002/stem.2372

50. Phinney DG, Di Giuseppe M, Njah J, Sala E, Shiva S, St Croix CM, et al. Mesenchymal Stem Cells Use Extracellular Vesicles to Outsource Mitophagy and Shuttle Micrornas. Nat Commun (2015) 6:8472. doi: 10.1038/ ncomms 9472

51. Pers YM, Quentin J, Feirreira R, Espinoza F, Abdellaoui N, Erkilic N, et al. Injection of Adipose-Derived Stromal Cells in the Knee of Patients With Severe Osteoarthritis has a Systemic Effect and Promotes an AntiInflammatory Phenotype of Circulating Immune Cells. Theranostics (2018) 8:5519-28. doi: 10.7150/thno.27674

52. Lu L, Dai C, Zhang Z, Du H, Li S, Ye P, et al. Treatment of Knee Osteoarthritis With Intra-Articular Injection of Autologous AdiposeDerived Mesenchymal Progenitor Cells: A Prospective, Randomized, Double-Blind, Active-Controlled, Phase IIb Clinical Trial. Stem Cell Res Ther (2019) 10:143. doi: 10.1186/s13287-019-1248-3

53. Zhao X, Ruan J, Tang H, Li J, Shi Y, Li M, et al. Multi-Compositional MRI Evaluation of Repair Cartilage in Knee Osteoarthritis With Treatment of Allogeneic Human Adipose-Derived Mesenchymal Progenitor Cells. Stem Cell Res Ther (2019) 10:308. doi: 10.1186/s13287-019-1406-7

54. Luz-Crawford P, Djouad F, Toupet K, Bony C, Franquesa M, Hoogduijn MJ, et al. Mesenchymal Stem Cell-Derived Interleukin 1 Receptor Antagonist Promotes Macrophage Polarization and Inhibits B Cell Differentiation. Stem Cells (2016) 34:483-92. doi: 10.1002/stem.2254

55. Song WJ, Li Q, Ryu MO, Ahn JO, Ha Bhang D, Chan Jung Y, et al. Tsg-6 Secreted by Human Adipose Tissue-derived Mesenchymal Stem Cells Ameliorates DSS-Induced Colitis by Inducing M2 Macrophage Polarization in Mice. Sci Rep (2017) 7:5187. doi: 10.1038/s41598-017-04766-7

56. Roddy GW, Oh JY, Lee RH, Bartosh TJ, Ylostalo J, Coble K, et al. Action At a Distance: Systemically Administered Adult Stem/Progenitor Cells (Mscs) Reduce Inflammatory Damage to the Cornea Without Engraftment and Primarily by Secretion of TNF-alpha Stimulated Gene/Protein 6. Stem Cells (2011) 29:1572-9. doi: 10.1002/stem.708

57. Danchuk S, Ylostalo JH, Hossain F, Sorge R, Ramsey A, Bonvillain RW, et al. Human Multipotent Stromal Cells Attenuate Lipopolysaccharide-Induced Acute Lung Injury in Mice Via Secretion of Tumor Necrosis Factor-AlphaInduced Protein 6. Stem Cell Res Ther (2011) 2:27. doi: 10.1186/scrt68

58. Wang N, Li Q, Zhang L, Lin H, Hu J, Li D, et al. Mesenchymal Stem Cells Attenuate Peritoneal Injury Through Secretion of TSG-6. PloS One (2012) 7: e43768. doi: 10.1371/journal.pone.0043768

59. Song HB, Park SY, Ko JH, Park JW, Yoon CH, Kim DH, et al. Mesenchymal Stromal Cells Inhibit Inflammatory Lymphangiogenesis in the Cornea by Suppressing Macrophage in a TSG-6-Dependent Manner. Mol Ther (2018) 26:162-72. doi: 10.1016/j.ymthe.2017.09.026

60. Deng Y, Zhang Y, Ye L, Zhang T, Cheng J, Chen G, et al. Umbilical Cordderived Mesenchymal Stem Cells Instruct Monocytes Towards an IL10producing Phenotype by Secreting IL6 and HGF. Sci Rep (2016) 6:37566. doi: $10.1038 /$ srep37566

61. Melief SM, Geutskens SB, Fibbe WE, Roelofs H. Multipotent Stromal Cells Skew Monocytes Towards an Anti-Inflammatory interleukin-10-producing Phenotype by Production of Interleukin-6. Haematologica (2013) 98:888-95. doi: 10.3324/haematol.2012.078055

62. Giri J, Das R, Nylen E, Chinnadurai R, Galipeau J. CCL2 and CXCL12 Derived From Mesenchymal Stromal Cells Cooperatively Polarize Il-10+ Tissue Macrophages to Mitigate Gut Injury. Cell Rep (2020) 30:1923-1934 e1924. doi: 10.1016/j.celrep.2020.01.047

63. Liu S, Liu F, Zhou Y, Jin B, Sun Q, Guo S. Immunosuppressive Property of MSCs Mediated by Cell Surface Receptors. Front Immunol (2020) 11:1076. doi: 10.3389/fimmu.2020.01076
64. Ren G, Zhao X, Zhang L, Zhang J, L'Huillier A, Ling W, et al. Inflammatory Cytokine-Induced Intercellular Adhesion Molecule-1 and Vascular Cell Adhesion Molecule-1 in Mesenchymal Stem Cells are Critical for Immunosuppression. J Immunol (2010) 184:2321-8. doi: 10.4049/ jimmunol.0902023

65. Takizawa N, Okubo N, Kamo M, Chosa N, Mikami T, Suzuki K, et al. Bone Marrow-Derived Mesenchymal Stem Cells Propagate Immunosuppressive/ Anti-Inflammatory Macrophages in Cell-to-Cell Contact-Independent and -Dependent Manners Under Hypoxic Culture. Exp Cell Res (2017) 358:41120. doi: 10.1016/j.yexcr.2017.07.014

66. Espagnolle N, Balguerie A, Arnaud E, Sensebe L, Varin A. CD54-Mediated Interaction With Pro-inflammatory Macrophages Increases the Immunosuppressive Function of Human Mesenchymal Stromal Cells. Stem Cell Rep (2017) 8:961-76. doi: 10.1016/j.stemcr.2017.02.008

67. Tang B, Li X, Liu Y, Chen X, Li X, Chu Y, et al. The Therapeutic Effect of ICAM-1-Overexpressing Mesenchymal Stem Cells on Acute Graft-VersusHost Disease. Cell Physiol Biochem (2018) 46:2624-35. doi: 10.1159/ 000489689

68. Fan J, Tang X, Wang Q, Zhang Z, Wu S, Li W, et al. Mesenchymal Stem Cells Alleviate Experimental Autoimmune Cholangitis Through Immunosuppression and Cytoprotective Function Mediated by Galectin-9. Stem Cell Res Ther (2018) 9:237. doi: 10.1186/s13287-0180979-x

69. Kim SN, Lee HJ, Jeon MS, Yi T. and Song Su Galectin-9 is Involved in Immunosuppression Mediated by Human Bone Marrow-derived Clonal Mesenchymal Stem Cells. Immune Netw (2015) 15:241-51. doi: 10.4110/ in.2015.15.5.241

70. Li ZH, Wang LL, Liu H, Muyayalo KP, Huang XB, Mor G, et al. Galectin-9 Alleviates Lps-Induced Preeclampsia-Like Impairment in Rats Via Switching Decidual Macrophage Polarization to M2 Subtype. Front Immunol (2018) 9:3142. doi: 10.3389/fimmu.2018.03142

71. Zhang W, Zhang Y, He Y, Wang X, Fang Q. Lipopolysaccharide Mediates Time-Dependent Macrophage M1/M2 Polarization Through the Tim-3/ Galectin-9 Signalling Pathway. Exp Cell Res (2019) 376:124-32. doi: 10.1016/ j.yexcr.2019.02.007

72. Zanier ER, Pischiutta F, Riganti L, Marchesi F, Turola E, Fumagalli S, et al. Bone Marrow Mesenchymal Stromal Cells Drive Protective M2 Microglia Polarization After Brain Trauma. Neurotherapeutics (2014) 11:679-95. doi: 10.1007/s13311-014-0277-y

73. Pietila M, Lehtonen S, Tuovinen E, Lahteenmaki K, Laitinen S, Leskela HV, et al. CD200 Positive Human Mesenchymal Stem Cells Suppress TNF-alpha Secretion From CD200 Receptor Positive Macrophage-Like Cells. PloS One (2012) 7:e31671. doi: 10.1371/journal.pone.0031671

74. Amouzegar A, Mittal SK, Sahu A, Sahu SK, Chauhan SK. Mesenchymal Stem Cells Modulate Differentiation of Myeloid Progenitor Cells During Inflammation. Stem Cells (2017) 35:1532-41. doi: 10.1002/stem.2611

75. Li Z, Ye H, Cai X, Sun W, He B, Yang Z, et al. Bone Marrow-Mesenchymal Stem Cells Modulate Microglial Activation in the Peri-Infarct Area in Rats During the Acute Phase of Stroke. Brain Res Bull (2019) 153:324-33. doi: 10.1016/j.brainresbull.2019.10.001

76. Wu W, Lan Q, Lu H, Xu J, Zhu A, Fang W, et al. Human Amnion Mesenchymal Cells Negative Co-Stimulatory Molecules PD-L1 Expression and its Capacity of Modulating Microglial Activation of CNS. Cell Biochem Biophys (2014) 69:35-45. doi: 10.1007/s12013-013-9763-9

77. Thery C, Ostrowski M, Segura E. Membrane Vesicles as Conveyors of Immune Responses. Nat Rev Immunol (2009) 9:581-93. doi: 10.1038/ nri2567

78. Cao L, Xu H, Wang G, Liu M, Tian D, Yuan Z. Extracellular Vesicles Derived From Bone Marrow Mesenchymal Stem Cells Attenuate Dextran Sodium Sulfate-Induced Ulcerative Colitis by Promoting M2 Macrophage Polarization. Int Immunopharmacol (2019) 72:264-74. doi: 10.1016/ j.intimp.2019.04.020

79. Mao F, Wu Y, Tang X, Kang J, Zhang B, Yan Y, et al. Exosomes Derived From Human Umbilical Cord Mesenchymal Stem Cells Relieve Inflammatory Bowel Disease in Mice. BioMed Res Int (2017) 2017:5356760. doi: 10.1155/2017/5356760

80. Wu H, Fan H, Shou Z, Xu M, Chen Q, Ai C, et al. Extracellular Vesicles Containing miR-146a Attenuate Experimental Colitis by Targeting TRAF6 
and IRAK1. Int Immunopharmacol (2019) 68:204-12. doi: 10.1016/ j.intimp.2018.12.043

81. Yang J, Liu XX, Fan H, Tang Q, Shou ZX, Zuo DM, et al. Extracellular Vesicles Derived From Bone Marrow Mesenchymal Stem Cells Protect Against Experimental Colitis Via Attenuating Colon Inflammation, Oxidative Stress and Apoptosis. PloS One (2015) 10:e0140551. doi: 10.1371/journal.pone.0140551

82. Song Y, Dou H, Li X, Zhao X, Li Y, Liu D, et al. Exosomal Mir-146a Contributes to the Enhanced Therapeutic Efficacy of Interleukin-1betaPrimed Mesenchymal Stem Cells Against Sepsis. Stem Cells (2017) 35:1208-21. doi: 10.1002/stem.2564

83. Xu R, Zhang F, Chai R, Zhou W, Hu M, Liu B, et al. Exosomes Derived From Pro-Inflammatory Bone Marrow-Derived Mesenchymal Stem Cells Reduce Inflammation and Myocardial Injury Via Mediating Macrophage Polarization. J Cell Mol Med (2019) 23:7617-31. doi: 10.1111/jcmm.14635

84. Mitchell R, Mellows B, Sheard J, Antonioli M, Kretz O, Chambers D, et al. Secretome of Adipose-Derived Mesenchymal Stem Cells Promotes Skeletal Muscle Regeneration Through Synergistic Action of Extracellular Vesicle Cargo and Soluble Proteins. Stem Cell Res Ther (2019) 10:116. doi: 10.1186/ s13287-019-1213-1

85. He X, Dong Z, Cao Y, Wang H, Liu S, Liao L, et al. Msc-Derived Exosome Promotes M2 Polarization and Enhances Cutaneous Wound Healing. Stem Cells Int (2019) 2019:7132708. doi: 10.1155/2019/7132708

86. Ti D, Hao H, Tong C, Liu J, Dong L, Zheng J, et al. LPS-Preconditioned Mesenchymal Stromal Cells Modify Macrophage Polarization for Resolution of Chronic Inflammation Via Exosome-Shuttled Let-7b. J Transl Med (2015) 13:308. doi: 10.1186/s12967-015-0642-6

87. Grabiec AM, Hussell T. The Role of Airway Macrophages in Apoptotic Cell Clearance Following Acute and Chronic Lung Inflammation. Semin Immunopathol (2016) 38:409-23. doi: 10.1007/s00281-016-0555-3

88. Li JW, Wei L, Han Z, Chen Z. Mesenchymal Stromal Cells-Derived Exosomes Alleviate Ischemia/Reperfusion Injury in Mouse Lung by Transporting Anti-Apoptotic Mir-21-5p. Eur J Pharmacol (2019) 852:6876. doi: 10.1016/j.ejphar.2019.01.022

89. Devaney J, Horie S, Masterson C, Elliman S, Barry F, O’Brien T, et al. Human Mesenchymal Stromal Cells Decrease the Severity of Acute Lung Injury Induced by E. Coli in the Rat. Thorax (2015) 70:625-35. doi: 10.1136/ thoraxjnl-2015-206813

90. Tsuchiya A, Takeuchi S, Iwasawa T, Kumagai M, Sato T, Motegi S, et al. Therapeutic Potential of Mesenchymal Stem Cells and Their Exosomes in Severe Novel Coronavirus Disease 2019 (COVID-19) Cases. Inflammation Regener (2020) 40:14. doi: 10.1186/s41232-020-00121-y

91. Rustom A, Saffrich R, Markovic I, Walther P, Gerdes HH. Nanotubular Highways for Intercellular Organelle Transport. Science (2004) 303:1007-10. doi: $10.1126 /$ science. 1093133

92. Spees JL, Olson SD, Whitney MJ. and Prockop Dj Mitochondrial Transfer Between Cells can Rescue Aerobic Respiration. Proc Natl Acad Sci USA (2006) 103:1283-8. doi: 10.1073/pnas.0510511103

93. Paliwal S, Chaudhuri R, Agrawal A, Mohanty S. Regenerative Abilities of Mesenchymal Stem Cells Through Mitochondrial Transfer. J BioMed Sci (2018) 25:31. doi: 10.1186/s12929-018-0429-1

94. Rodriguez AM, Nakhle J, Griessinger E, Vignais ML. Intercellular Mitochondria Trafficking Highlighting the Dual Role of Mesenchymal Stem Cells as Both Sensors and Rescuers of Tissue Injury. Cell Cycle (2018) 17:712-21. doi: 10.1080/15384101.2018.1445906

95. Freire-de-Lima CG, Xiao YQ, Gardai SJ, Bratton DL, Schiemann WP, Henson PM. Apoptotic Cells, Through Transforming Growth Factor-Beta, Coordinately Induce Anti-Inflammatory and Suppress Pro-Inflammatory Eicosanoid and NO Synthesis in Murine Macrophages. J Biol Chem (2006) 281:38376-84. doi: 10.1074/jbc.M605146200

96. Voll RE, Herrmann M, Roth EA, Stach C, Kalden JR, Girkontaite I. Immunosuppressive Effects of Apoptotic Cells. Nature (1997) 390:350-1. doi: $10.1038 / 37022$

97. Ariel A, Maridonneau-Parini I, Rovere-Querini P, Levine JS, Muhl H. Macrophages in Inflammation and its Resolution. Front Immunol (2012) 3:324. doi: $10.3389 /$ fimmu.2012.00324

98. Zhang Z, Huang S, Wu S, Qi J, Li W, Liu S, et al. Clearance of Apoptotic Cells by Mesenchymal Stem Cells Contributes to Immunosuppression
Via PGE2. EBioMedicine (2019) 45:341-50. doi: 10.1016/j.ebiom. 2019.06.016

99. Akiyama K, Chen C, Wang D, Xu X, Qu C, Yamaza T, et al. MesenchymalStem-Cell-Induced Immunoregulation Involves FAS-Ligand-/FASMediated T Cell Apoptosis. Cell Stem Cell (2012) 10:544-55. doi: 10.1016/ j.stem.2012.03.007

100. Galleu A, Riffo-Vasquez Y, Trento C, Lomas C, Dolcetti L, Cheung TS, et al. Apoptosis in Mesenchymal Stromal Cells Induces In Vivo RecipientMediated Immunomodulation. Sci Transl Med (2017) 9(416):eaam7828. doi: 10.1126/scitranslmed.aam7828

101. Ankrum JA, Ong JF, Karp JM. Mesenchymal Stem Cells: Immune Evasive, Not Immune Privileged. Nat Biotechnol (2014) 32:252-60. doi: 10.1038/ nbt.2816

102. Berglund AK, Fortier LA, Antczak DF, Schnabel LV. Immunoprivileged No More: Measuring the Immunogenicity of Allogeneic Adult Mesenchymal Stem Cells. Stem Cell Res Ther (2017) 8:288. doi: 10.1186/s13287-017-0742-8

103. Galipeau J, Sensebe L. Mesenchymal Stromal Cells: Clinical Challenges and Therapeutic Opportunities. Cell Stem Cell (2018) 22:824-33. doi: 10.1016/ j.stem.2018.05.004

104. Mezey E, Nemeth K. Mesenchymal Stem Cells and Infectious Diseases: Smarter Than Drugs. Immunol Lett (2015) 168:208-14. doi: 10.1016/ j.imlet.2015.05.020

105. Sutton MT, Fletcher D, Ghosh SK, Weinberg A, van Heeckeren R, Kaur S, et al. Antimicrobial Properties of Mesenchymal Stem Cells: Therapeutic Potential for Cystic Fibrosis Infection, and Treatment. Stem Cells Int (2016) 2016:5303048. doi: 10.1155/2016/5303048

106. Chow L, Johnson V, Impastato R, Coy J, Strumpf A, Dow S. Antibacterial Activity of Human Mesenchymal Stem Cells Mediated Directly by Constitutively Secreted Factors and Indirectly by Activation of Innate Immune Effector Cells. Stem Cells Transl Med (2020) 9:235-49. doi: 10.1002/sctm.19-0092

107. Krasnodembskaya A, Song Y, Fang X, Gupta N, Serikov V, Lee JW, et al. Antibacterial Effect of Human Mesenchymal Stem Cells is Mediated in Part From Secretion of the Antimicrobial Peptide LL-37. Stem Cells (2010) 28:2229-38. doi: 10.1002/stem.544

108. Sung DK, Chang YS, Sung SI, Yoo HS, Ahn SY, Park WS. Antibacterial Effect of Mesenchymal Stem Cells Against Escherichia Coli is Mediated by Secretion of Beta- Defensin- 2 Via Toll- Like Receptor 4 Signalling. Cell Microbiol (2016) 18:424-36. doi: 10.1111/cmi.12522

109. Alcayaga-Miranda F, Cuenca J, Martin A, Contreras L, Figueroa FE, Khoury M. Combination Therapy of Menstrual Derived Mesenchymal Stem Cells and Antibiotics Ameliorates Survival in Sepsis. Stem Cell Res Ther (2015) 6:199. doi: 10.1186/s13287-015-0192-0

110. Gupta N, Krasnodembskaya A, Kapetanaki M, Mouded M, Tan X, Serikov V, et al. Mesenchymal Stem Cells Enhance Survival and Bacterial Clearance in Murine Escherichia Coli Pneumonia. Thorax (2012) 67:533-9. doi: 10.1136/ thoraxjnl-2011-201176

111. Monsarrat P, Kemoun P, Casteilla L, Planat-Benard V. Broad-Spectrum Antibacterial Effects of Human Adipose-Derived Stromal Cells. Stem Cells Int (2019) 2019:5389629. doi: 10.1155/2019/5389629

112. Bahroudi M, Bakhshi B, Soudi S, Najar-Peerayeh S. Antibacterial and Antibiofilm Activity of Bone Marrow-Derived Human Mesenchymal Stem Cells Secretome Against Vibrio Cholerae. Microb Pathog (2020) 139:103867. doi: 10.1016/j.micpath.2019.103867

113. Le Blanc K, Mougiakakos D. Multipotent Mesenchymal Stromal Cells and the Innate Immune System. Nat Rev Immunol (2012) 12:383-96. doi: 10.1038/nri3209

114. Monsel A, Zhu YG, Gennai S, Hao Q, Hu S, Rouby JJ, et al. Therapeutic Effects of Human Mesenchymal Stem Cell-Derived Microvesicles in Severe Pneumonia in Mice. Am J Respir Crit Care Med (2015) 192:324-36. doi: 10.1164/rccm.201410-1765OC

115. Sisto F, Bonomi A, Cavicchini L, Cocce V, Scaltrito MM, Bondiolotti G, et al. Human Mesenchymal Stromal Cells can Uptake and Release Ciprofloxacin, Acquiring In Vitro Anti-Bacterial Activity. Cytotherapy (2014) 16:181-90. doi: 10.1016/j.jcyt.2013.11.009

116. Charriere G, Cousin B, Arnaud E, Andre M, Bacou F, Penicaud L, et al. Preadipocyte Conversion to Macrophage. Evidence Plasticity J Biol Chem (2003) 278:9850-5. doi: 10.1074/jbc.M210811200 
117. Saillan-Barreau C, Cousin B, Andre M, Villena P, Casteilla L, Penicaud L. Human Adipose Cells as Candidates in Defense and Tissue Remodeling Phenomena. Biochem Biophys Res Commun (2003) 309:502-5. doi: 10.1016/ j.bbrc.2003.08.034

118. Hotamisligil GS. Inflammation and Metabolic Disorders. Nature (2006) 444:860-7. doi: 10.1038/nature05485

119. Charriere GM, Cousin B, Arnaud E, Saillan-Barreau C, Andre M, Massoudi A, et al. Macrophage Characteristics of Stem Cells Revealed by Transcriptome Profiling. Exp Cell Res (2006) 312:3205-14. doi: 10.1016/ j.yexcr.2006.06.034

120. Franz A, Wood W, Martin P. Fat Body Cells are Motile and Actively Migrate to Wounds to Drive Repair and Prevent Infection. Dev Cell (2018) 44:46070.e463. doi: 10.1016/j.devcel.2018.01.026

121. Cani PD, Amar J, Iglesias MA, Poggi M, Knauf C, Bastelica D, et al. Metabolic Endotoxemia Initiates Obesity and Insulin Resistance. Diabetes (2007) 56:1761-72. doi: 10.2337/db06-1491

122. Combs TP, Nagajyothi, Mukherjee S, de Almeida CJ, Jelicks LA, Schubert W, et al. The Adipocyte as an Important Target Cell for Trypanosoma Cruzi Infection. J Biol Chem (2005) 280:24085-94. doi: 10.1074/jbc.M412802200

123. Koethe JR, Hulgan T, Niswender K. Adipose Tissue and Immune Function: A Review of Evidence Relevant to HIV Infection. J Infect Dis (2013) 208:1194-201. doi: 10.1093/infdis/jit324

124. Randall PJ, Hsu NJ, Quesniaux V, Ryffel B, Jacobs M. Mycobacterium Tuberculosis Infection of the 'Non-Classical Immune Cell'. Immunol Cell Biol (2015) 93:789-95. doi: 10.1038/icb.2015.43

125. Roingeard P, Melo RC. Lipid Droplet Hijacking by Intracellular Pathogens. Cell Microbiol (2017) 19(1):e47388. doi: 10.1111/cmi.12688

126. Tanowitz HB, Scherer PE, Mota MM, Figueiredo LM. Adipose Tissue: A Safe Haven for Parasites? Trends Parasitol (2017) 33:276-84. doi: 10.1016/ j.pt.2016.11.008

127. Khan A, Hunter RL, Jagannath C. Emerging Role of Mesenchymal Stem Cells During Tuberculosis: The Fifth Element in Cell Mediated Immunity. Tuberculosis (Edinb) (2016) 101S:S45-52. doi: 10.1016/ j.tube.2016.09.019

128. Krausgruber T, Fortelny N, Fife-Gernedl V, Senekowitsch M, Schuster LC, Lercher A, et al. Structural Cells are Key Regulators of Organ-Specific Immune Responses. Nature (2020) 583:296-302. doi: 10.1038/s41586-0202424-4

129. Kalluri R. The Biology and Function of Fibroblasts in Cancer. Nat Rev Cancer (2016) 16:582-98. doi: 10.1038/nrc.2016.73

130. Bernardo ME, Fibbe WE. Mesenchymal Stromal Cells: Sensors and Switchers of Inflammation. Cell Stem Cell (2013) 13:392-402. doi: 10.1016/ j.stem.2013.09.006

131. Waterman RS, Tomchuck SL, Henkle SL, Betancourt AM. A New Mesenchymal Stem Cell (MSC) Paradigm: Polarization Into a ProInflammatory $\mathrm{MSC} 1$ or an Immunosuppressive MSC2 Phenotype. PloS One (2010) 5:e10088. doi: 10.1371/journal.pone.0010088

132. Lercher A, Baazim H, Bergthaler A. Systemic Immunometabolism: Challenges and Opportunities. Immunity (2020) 53:496-509. doi: 10.1016/ j.immuni.2020.08.012

133. Odegaard JI, Chawla A. The Immune System as a Sensor of the Metabolic State. Immunity (2013) 38:644-54. doi: 10.1016/j.immuni.2013.04.001

134. Pearce EL, Pearce EJ. Metabolic Pathways in Immune Cell Activation and Quiescence. Immunity (2013) 38:633-43. doi: 10.1016/j.immuni.2013.04.005

135. Biswas SK, Mantovani A. Orchestration of Metabolism by Macrophages. Cell Metab (2012) 15:432-7. doi: 10.1016/j.cmet.2011.11.013

136. Van den Bossche J, O’Neill LA, Menon D. Macrophage Immunometabolism: Where are We (Going)? Trends Immunol (2017) 38:395-406. doi: 10.1016/ j.it.2017.03.001

137. Mills EL, Kelly B, Logan A, Costa ASH, Varma M, Bryant CE, et al. Succinate Dehydrogenase Supports Metabolic Repurposing of Mitochondria to Drive Inflammatory Macrophages. Cell (2016) 167:457-470 e413. doi: 10.1016/ j.cell.2016.08.064

138. Sadiku P, Walmsley SR. Hypoxia and the Regulation of Myeloid Cell Metabolic Imprinting: Consequences for the Inflammatory Response. EMBO Rep (2019) 20(5):e47388. doi: 10.15252/embr.201847388

139. Selleri S, Bifsha P, Civini S, Pacelli C, Dieng MM, Lemieux W, et al. Human Mesenchymal Stromal Cell-Secreted Lactate Induces M2-macrophage
Differentiation by Metabolic Reprogramming. Oncotarget (2016) 7:30193210. doi: $10.18632 /$ oncotarget. 8623

140. Fiaschi T, Marini A, Giannoni E, Taddei ML, Gandellini P, De Donatis A, et al. Reciprocal Metabolic Reprogramming Through Lactate Shuttle Coordinately Influences Tumor-Stroma Interplay. Cancer Res (2012) 72:5130-40. doi: 10.1158/0008-5472.CAN-12-1949

141. Krstic J, Trivanovic D, Jaukovic A, Santibanez JF, Bugarski D. Metabolic Plasticity of Stem Cells and Macrophages in Cancer. Front Immunol (2017) 8:939. doi: 10.3389/fimmu.2017.00939

142. Saraswati S, Guo Y, Atkinson J, Young PP. Prolonged Hypoxia Induces Monocarboxylate Transporter-4 Expression in Mesenchymal Stem Cells Resulting in a Secretome That is Deleterious to Cardiovascular Repair. Stem Cells (2015) 33:1333-44. doi: 10.1002/stem.1935

143. Stavely R, Nurgali K. The Emerging Antioxidant Paradigm of Mesenchymal Stem Cell Therapy. Stem Cells Transl Med (2020) 9:985-1006. doi: 10.1002/ sctm.19-0446

144. Kim WS, Park BS, Kim HK, Park JS, Kim KJ, Choi JS, et al. Evidence Supporting Antioxidant Action of Adipose-Derived Stem Cells: Protection of Human Dermal Fibroblasts From Oxidative Stress. J Dermatol Sci (2008) 49:133-42. doi: 10.1016/j.jdermsci.2007.08.004

145. Ma Z, Song G, Zhao D, Liu D, Liu X, Dai Y, et al. Bone Marrow-Derived Mesenchymal Stromal Cells Ameliorate Severe Acute Pancreatitis in Rats Via hemeoxygenase-1-mediated Anti-Oxidant and Anti-Inflammatory Effects. Cytotherapy (2019) 21:162-74. doi: 10.1016/j.jcyt.2018.11.013

146. Pan H, Guan D, Liu X, Li J, Wang L, Wu J, et al. SIRT6 Safeguards Human Mesenchymal Stem Cells From Oxidative Stress by Coactivating NRF2. Cell Res (2016) 26:190-205. doi: 10.1038/cr.2016.4

147. Valle-Prieto A, Conget PA. Human Mesenchymal Stem Cells Efficiently Manage Oxidative Stress. Stem Cells Dev (2010) 19:1885-93. doi: 10.1089/ scd.2010.0093

148. Cizkova D, Rosocha J, Vanicky I, Radonak J, Galik J, Cizek M. Induction of Mesenchymal Stem Cells Leads to HSP72 Synthesis and Higher Resistance to Oxidative Stress. Neurochem Res (2006) 31:1011-20. doi: 10.1007/s11064006-9107-x

149. Kiani AA, Kazemi A, Halabian R, Mohammadipour M, Jahanian-Najafabadi A, Roudkenar MH. HIF-1alpha Confers Resistance to Induced Stress in Bone Marrow-Derived Mesenchymal Stem Cells. Arch Med Res (2013) 44:185-93. doi: 10.1016/j.arcmed.2013.03.006

150. Mohammadzadeh M, Halabian R, Gharehbaghian A, Amirizadeh N, Jahanian-Najafabadi A, Roushandeh AM, et al. Nrf-2 Overexpression in Mesenchymal Stem Cells Reduces Oxidative Stress-Induced Apoptosis and Cytotoxicity. Cell Stress Chaperones (2012) 17:553-65. doi: 10.1007/s12192012-0331-9

151. Domingues CC, Kundu N, Kropotova Y, Ahmadi N, Sen S. AntioxidantUpregulated Mesenchymal Stem Cells Reduce Inflammation and Improve Fatty Liver Disease in Diet-Induced Obesity. Stem Cell Res Ther (2019) 10:280. doi: 10.1186/s13287-019-1393-8

152. Xia C, Zeng Z, Fang B, Tao M, Gu C, Zheng L, et al. Mesenchymal Stem CellDerived Exosomes Ameliorate Intervertebral Disc Degeneration Via AntiOxidant and Anti-Inflammatory Effects. Free Radic Biol Med (2019) 143:115. doi: 10.1016/j.freeradbiomed.2019.07.026

153. Giacoppo S, Thangavelu SR, Diomede F, Bramanti P, Conti P, Trubiani O, et al. Anti-Inflammatory Effects of Hypoxia-Preconditioned Human Periodontal Ligament Cell Secretome in an Experimental Model of Multiple Sclerosis: A Key Role of IL-37. FASEB J (2017) 31:5592-608. doi: $10.1096 / f j .201700524 \mathrm{R}$

154. Lin T, Pajarinen J, Nabeshima A, Lu L, Nathan K, Jamsen E, et al. Preconditioning of Murine Mesenchymal Stem Cells Synergistically Enhanced Immunomodulation and Osteogenesis. Stem Cell Res Ther (2017) 8:277. doi: 10.1186/s13287-017-0730-z

155. Philipp D, Suhr L, Wahlers T, Choi YH, Paunel-Gorgulu A. Preconditioning of Bone Marrow-Derived Mesenchymal Stem Cells Highly Strengthens Their Potential to Promote IL-6-dependent M2b Polarization. Stem Cell Res Ther (2018) 9:286. doi: 10.1186/s13287-018-1039-2

156. Redondo-Castro E, Cunningham C, Miller J, Martuscelli L, Aoulad-Ali S, Rothwell NJ, et al. Interleukin-1 Primes Human Mesenchymal Stem Cells Towards an Anti-Inflammatory and Pro-Trophic Phenotype In Vitro. Stem Cell Res Ther (2017) 8:79. doi: 10.1186/s13287-017-0531-4 
157. Saparov A, Ogay V, Nurgozhin T, Jumabay M, Chen WC. Preconditioning of Human Mesenchymal Stem Cells to Enhance Their Regulation of the Immune Response. Stem Cells Int (2016) 2016:3924858. doi: 10.1155/2016/ 3924858

158. Laporte C, Tubbs E, Cristante J, Gauchez AS, Pesenti S, Lamarche F, et al. Human Mesenchymal Stem Cells Improve Rat Islet Functionality Under Cytokine Stress With Combined Upregulation of Heme Oxygenase-1 and Ferritin. Stem Cell Res Ther (2019) 10:85. doi: 10.1186/s13287-019-1190-4

159. Alissafi T, Kalafati L, Lazari M, Filia A, Kloukina I, Manifava M, et al. Mitochondrial Oxidative Damage Underlies Regulatory T Cell Defects in Autoimmunity. Cell Metab (2020) 32:591-604 e597. doi: 10.1016/ j.cmet.2020.07.001

160. Liu PS, Ho PC. Mitochondria: A Master Regulator in Macrophage and T Cell Immunity. Mitochondrion (2018) 41:45-50. doi: 10.1016/j.mito.2017.11.002

161. Meyer A, Laverny G, Bernardi L, Charles AL, Alsaleh G, Pottecher J, et al. Mitochondria: An Organelle of Bacterial Origin Controlling Inflammation. Front Immunol (2018) 9:536. doi: 10.3389/fimmu.2018.00536

162. Zuo H, Trombetta-Lima M, Heijink IH, van der Veen C, Hesse L, Faber KN, et al. A-Kinase Anchoring Proteins Diminish TGF-Betal/Cigarette SmokeInduced Epithelial-To-Mesenchymal Transition. Cells (2020) 9(2):356. doi: 10.3390/cells9020356

163. Feng Y, Zhu R, Shen J, Wu J, Lu W, Zhang J, et al. Human Bone Marrow Mesenchymal Stem Cells Rescue Endothelial Cells Experiencing Chemotherapy Stress by Mitochondrial Transfer Via Tunneling Nanotubes. Stem Cells Dev (2019) 28:674-82. doi: 10.1089/scd.2018.0248

164. Islam MN, Das SR, Emin MT, Wei M, Sun L, Westphalen K, et al. Mitochondrial Transfer From Bone-Marrow-Derived Stromal Cells to Pulmonary Alveoli Protects Against Acute Lung Injury. Nat Med (2012) 18:759-65. doi: $10.1038 / \mathrm{nm} .2736$

165. Liu K, Guo L, Zhou Z, Pan M. and Yan C Mesenchymal Stem Cells Transfer Mitochondria Into Cerebral Microvasculature and Promote Recovery From Ischemic Stroke. Microvasc Res (2019) 123:74-80. doi: 10.1016/ j.mvr.2019.01.001

166. Plotnikov EY, Khryapenkova TG, Vasileva AK, Marey MV, Galkina SI, Isaev NK, et al. Cell-to-Cell Cross-Talk Between Mesenchymal Stem Cells and Cardiomyocytes in Co-Culture. J Cell Mol Med (2008) 12:1622-31. doi: 10.1111/j.1582-4934.2007.00205.x

167. Morrison TJ, Jackson MV, Cunningham EK, Kissenpfennig A, McAuley DF, O'Kane CM, et al. Mesenchymal Stromal Cells Modulate Macrophages in Clinically Relevant Lung Injury Models by Extracellular Vesicle Mitochondrial Transfer. Am J Respir Crit Care Med (2017) 196:1275-86. doi: 10.1164/rccm.201701-01700C

168. Luz-Crawford P, Hernandez J, Djouad F, Luque-Campos N, Caicedo A, Carrere-Kremer S, et al. Mesenchymal Stem Cell Repression of Th17 Cells is Triggered by Mitochondrial Transfer. Stem Cell Res Ther (2019) 10:232. doi: 10.1186/s13287-019-1307-9

169. Mahrouf-Yorgov M, Augeul L, Da Silva CC, Jourdan M, Rigolet M, Manin S, et al. Mesenchymal Stem Cells Sense Mitochondria Released From Damaged Cells as Danger Signals to Activate Their Rescue Properties. Cell Death Differ (2017) 24:1224-38. doi: 10.1038/cdd.2017.51

170. Li C, Cheung MKH, Han S, Zhang Z, Chen L, Chen J, et al. Mesenchymal Stem Cells and Their Mitochondrial Transfer: A Double-Edged Sword. Biosci Rep (2019) 39(5):BSR20182417. doi: 10.1042/BSR20182417

171. Li M, Wang L, Wang Y, Zhang S, Zhou G, Lieshout R, et al. Mitochondrial Fusion Via OPA1 and MFN1 Supports Liver Tumor Cell Metabolism and Growth. Cells (2020) 9(1):121. doi: 10.3390/cells9010121

172. Newell C, Sabouny R, Hittel DS, Shutt TE, Khan A, Klein MS, et al. Mesenchymal Stem Cells Shift Mitochondrial Dynamics and Enhance Oxidative Phosphorylation in Recipient Cells. Front Physiol (2018) 9:1572. doi: 10.3389/fphys.2018.01572

173. Stab BR,2, Martinez L, Grismaldo A, Lerma A, Gutierrez ML, Barrera LA, et al. Mitochondrial Functional Changes Characterization in Young and Senescent Human Adipose Derived Mscs. Front Aging Neurosci (2016) 8:299. doi: $10.3389 /$ fnagi.2016.00299

174. Sorgdrager FJH, Naude PJW, Kema IP, Nollen EA, Deyn PP. Tryptophan Metabolism in Inflammaging: From Biomarker to Therapeutic Target. Front Immunol (2019) 10:2565. doi: 10.3389/fimmu.2019.02565
175. Wu KK. Control of Mesenchymal Stromal Cell Senescence by Tryptophan Metabolites. Int J Mol Sci (2021) 22(2):697. doi: 10.3390/ijms22020697

176. Rodriguez PC, Ochoa AC, Al-Khami AA. Arginine Metabolism in Myeloid Cells Shapes Innate and Adaptive Immunity. Front Immunol (2017) 8:93. doi: 10.3389/fimmu.2017.00093

177. Caplan H, Olson SD, Kumar A, George M, Prabhakara KS, Wenzel P, et al. Mesenchymal Stromal Cell Therapeutic Delivery: Translational Challenges to Clinical Application. Front Immunol (2019) 10:1645. doi: 10.3389/ fimmu.2019.01645

178. Chinnadurai R, Copland IB, Garcia MA, Petersen CT, Lewis CN, Waller EK, et al. Cryopreserved Mesenchymal Stromal Cells are Susceptible to T-Cell Mediated Apoptosis Which Is Partly Rescued by IFNgamma Licensing. Stem Cells (2016) 34:2429-42. doi: 10.1002/stem.2415

179. Sensebe L, Fleury-Cappellesso S. Biodistribution of Mesenchymal Stem/ Stromal Cells in a Preclinical Setting. Stem Cells Int (2013) 2013:678063. doi: $10.1155 / 2013 / 678063$

180. Braid LR, Wood CA, Wiese DM, Ford BN. Intramuscular Administration Potentiates Extended Dwell Time of Mesenchymal Stromal Cells Compared to Other Routes. Cytotherapy (2018) 20:232-44. doi: 10.1016/ j.jcyt.2017.09.013

181. Giri J, Galipeau J. Mesenchymal Stromal Cell Therapeutic Potency is Dependent Upon Viability, Route of Delivery, and Immune Match. Blood Adv (2020) 4:1987-97. doi: 10.1182/bloodadvances.2020001711

182. Menard C, Dulong J, Roulois D, Hebraud B, Verdiere L, Pangault C, et al. Integrated Transcriptomic, Phenotypic, and Functional Study Reveals Tissue-Specific Immune Properties of Mesenchymal Stromal Cells. Stem Cells (2020) 38:146-59. doi: 10.1002/stem.3077

183. Francois M, Copland IB, Yuan S, Romieu-Mourez R, Waller EK, Galipeau J. Cryopreserved Mesenchymal Stromal Cells Display Impaired Immunosuppressive Properties as a Result of Heat-Shock Response and Impaired Interferon-Gamma Licensing. Cytotherapy (2012) 14:147-52. doi: $10.3109 / 14653249.2011 .623691$

184. Oja S, Kaartinen T, Ahti M, Korhonen M, Laitinen A, Nystedt J. The Utilization of Freezing Steps in Mesenchymal Stromal Cell (Msc) Manufacturing: Potential Impact on Quality and Cell Functionality Attributes. Front Immunol (2019) 10:1627. doi: 10.3389/fimmu.2019.01627

185. Moll G, Alm JJ, Davies LC, von Bahr L, Heldring N, Stenbeck-Funke L, et al. Do Cryopreserved Mesenchymal Stromal Cells Display Impaired Immunomodulatory and Therapeutic Properties? Stem Cells (2014) 32:2430-42. doi: 10.1002/stem.1729

186. Chinnadurai R, Garcia MA, Sakurai Y, Lam WA, Kirk AD, Galipeau J, et al. Actin Cytoskeletal Disruption Following Cryopreservation Alters the Biodistribution of Human Mesenchymal Stromal Cells In Vivo. Stem Cell Rep (2014) 3:60-72. doi: 10.1016/j.stemcr.2014.05.003

187. Pollock K, Sumstad D, Kadidlo D, McKenna DH, Hubel A. Clinical Mesenchymal Stromal Cell Products Undergo Functional Changes in Response to Freezing. Cytotherapy (2015) 17:38-45. doi: 10.1016/ j.jcyt.2014.06.008

188. Kotze PG, Spinelli A, Warusavitarne J, Di Candido F, Sahnan K, Adegbola SO, et al. Darvadstrocel for the Treatment of Patients With Perianal Fistulas in Crohn's Disease. Drugs Today (Barc) (2019) 55:95-105. doi: 10.1358/ dot.2019.55.2.2914336

189. Panes J, Garcia-Olmo D, Van Assche G, Colombel JF, Reinisch W, Baumgart DC, et al. Long-Term Efficacy and Safety of Stem Cell Therapy (Cx601) for Complex Perianal Fistulas in Patients With Crohn's Disease. Gastroenterology (2018) 154:1334-42. doi: 10.1053/j.gastro.2017.12.020

190. Uccelli A, de Rosbo NK. The Immunomodulatory Function of Mesenchymal Stem Cells: Mode of Action and Pathways. Ann N Y Acad Sci (2015) 1351:114-26. doi: 10.1111/nyas.12815

191. Wang Y, Chen X, Cao W, Shi Y. Plasticity of Mesenchymal Stem Cells in Immunomodulation: Pathological and Therapeutic Implications. Nat Immunol (2014) 15:1009-16. doi: 10.1038/ni.3002

192. Chinnadurai R, Rajan D, Qayed M, Arafat D, Garcia M, Liu Y, et al. Potency Analysis of Mesenchymal Stromal Cells Using a Combinatorial Assay Matrix Approach. Cell Rep (2018) 22:2504-17. doi: 10.1016/j.celrep.2018.02.013

193. Ferreira JR, Teixeira GQ, Santos SG, Barbosa MA, Almeida-Porada G, Goncalves RM. Mesenchymal Stromal Cell Secretome: Influencing 
Therapeutic Potential by Cellular Pre-Conditioning. Front Immunol (2018) 9:2837. doi: $10.3389 /$ fimmu.2018.02837

194. Hu C, Li L. Preconditioning Influences Mesenchymal Stem Cell Properties In Vitro and In Vivo. J Cell Mol Med (2018) 22:1428-42. doi: 10.1111/ jcmm. 13492

195. Jiang W, Xu J. Immune Modulation by Mesenchymal Stem Cells. Cell Prolif (2020) 53:e12712. doi: 10.1111/cpr.12712

196. Krampera M. Mesenchymal Stromal Cell 'Licensing': A Multistep Process. Leukemia (2011) 25:1408-14. doi: 10.1038/leu.2011.108

197. Shi Y, Wang Y, Li Q, Liu K, Hou J, Shao C, et al. Immunoregulatory Mechanisms of Mesenchymal Stem and Stromal Cells in Inflammatory Diseases. Nat Rev Nephrol (2018) 14:493-507. doi: 10.1038/s41581-0180023-5

198. Oh J, Lee YD, Wagers AJ. Stem Cell Aging: Mechanisms, Regulators and Therapeutic Opportunities. Nat Med (2014) 20:870-80. doi: 10.1038/ nm.3651

199. Sethe S, Scutt A, Stolzing A. Aging of Mesenchymal Stem Cells. Ageing Res $\operatorname{Rev}(2006)$ 5:91-116. doi: 10.1016/j.arr.2005.10.001

200. Fafian-Labora JA, Morente-Lopez M, Arufe MC. Effect of Aging on Behaviour of Mesenchymal Stem Cells. World J Stem Cells (2019) 11:33746. doi: 10.4252/wjsc.v11.i6.337

201. Li Y, Wu Q, Wang Y, Li L, Bu H, Bao J. Senescence of Mesenchymal Stem Cells (Review). Int J Mol Med (2017) 39:775-82. doi: 10.3892/ ijmm.2017.2912

202. Turinetto V, Vitale E, Giachino C. Senescence in Human Mesenchymal Stem Cells: Functional Changes and Implications in Stem Cell-Based Therapy. Int J Mol Sci (2016) 17(7):1164. doi: 10.3390/ijms17071164

203. Lepperdinger G. Inflammation and Mesenchymal Stem Cell Aging. Curr Opin Immunol (2011) 23:518-24. doi: 10.1016/j.coi.2011.05.007

204. Lunyak VV, Amaro-Ortiz A, Gaur M. Mesenchymal Stem Cells Secretory Responses: Senescence Messaging Secretome and Immunomodulation Perspective. Front Genet (2017) 8:220. doi: 10.3389/fgene.2017.00220

205. Malaise O, Tachikart Y, Constantinides M, Mumme M, Ferreira-Lopez R, Noack S, et al. Mesenchymal Stem Cell Senescence Alleviates Their Intrinsic and SenoSuppressive Paracrine Properties Contributing to Osteoarthritis Development. Aging (Albany NY) (2019) 11:9128-46. doi: 10.18632/aging.102379

206. Vono R, Jover Garcia E, Spinetti G, Madeddu P. Oxidative Stress in Mesenchymal Stem Cell Senescence: Regulation by Coding and Noncoding Rnas. Antioxid Redox Signal (2018) 29:864-79. doi: 10.1089/ ars.2017.7294
207. Ho YH, Del Toro R, Rivera-Torres J, Rak J, Korn C, Garcia-Garcia A, et al. Remodeling of Bone Marrow Hematopoietic Stem Cell Niches Promotes Myeloid Cell Expansion During Premature or Physiological Aging. Cell Stem Cell (2019) 25:407-418 e406. doi: 10.1016/j.stem.2019.06.007

208. Collins JA, Diekman BO, Loeser RF. Targeting Aging for Disease Modification in Osteoarthritis. Curr Opin Rheumatol (2018) 30:101-7. doi: 10.1097/BOR.0000000000000456

209. Greene MA, Loeser RF. Aging-related Inflammation in Osteoarthritis. Osteoarthritis Cartilage (2015) 23:1966-71. doi: 10.1016/j.joca.2015.01.008

210. Ebersole JL, Graves CL, Gonzalez OA, Dawson D,3, Morford LA, Huja PE, et al. Aging, Inflammation, Immunity and Periodontal Disease. Periodontol 2000 (2016) 72:54-75. doi: 10.1111/prd.12135

211. Halim M, Halim A. The Effects of Inflammation, Aging and Oxidative Stress on the Pathogenesis of Diabetes Mellitus (Type 2 Diabetes). Diabetes Metab Syndr (2019) 13:1165-72. doi: 10.1016/j.dsx.2019.01.040

212. Lo Furno D, Mannino G, Giuffrida R. Functional Role of Mesenchymal Stem Cells in the Treatment of Chronic Neurodegenerative Diseases. J Cell Physiol (2018) 233:3982-99. doi: 10.1002/jcp.26192

213. Staff NP, Jones DT, Singer W. Mesenchymal Stromal Cell Therapies for Neurodegenerative Diseases. Mayo Clin Proc (2019) 94:892-905. doi: 10.1016/j.mayocp.2019.01.001

214. Oliva AA, McClain-Moss L, Pena A, Drouillard A, Hare JM. Allogeneic Mesenchymal Stem Cell Therapy: A Regenerative Medicine Approach to Geroscience. Aging Med (Milton) (2019) 2:142-6. doi: 10.1002/agm2.12079

215. Han X, Wang R, Zhou Y, Fei L, Sun H, Lai S, et al. Mapping the Mouse Cell Atlas by Microwell-Seq. Cell (2018) 172:1091-1107 e1017. doi: 10.1016/ j.cell.2018.02.001

216. Chen G, Yung R. Meta-Inflammaging At the Crossroad of Geroscience. Aging Med (Milton) (2019) 2:157-61. doi: 10.1002/agm2.12078

Conflict of Interest: The authors declare that the research was conducted in the absence of any commercial or financial relationships that could be construed as a potential conflict of interest.

Copyright $\odot 2021$ Planat-Benard, Varin and Casteilla. This is an open-access article distributed under the terms of the Creative Commons Attribution License (CC BY). The use, distribution or reproduction in other forums is permitted, provided the original author(s) and the copyright owner(s) are credited and that the original publication in this journal is cited, in accordance with accepted academic practice. No use, distribution or reproduction is permitted which does not comply with these terms. 